\title{
An Understanding of Lattice Strain, Defects and Disorder in Nuclear Graphite
}

DOI:

10.1016/j.carbon.2017.08.070

\section{Document Version}

Accepted author manuscript

Link to publication record in Manchester Research Explorer

\section{Citation for published version (APA):}

Krishna, R., Wade, J., Jones, A., Lasithiotakis, M., Mummery, P., \& Marsden, B. (2017). An Understanding of Lattice Strain, Defects and Disorder in Nuclear Graphite. Carbon, 124, 314-333.

https://doi.org/10.1016/j.carbon.2017.08.070

\section{Published in:}

Carbon

\section{Citing this paper}

Please note that where the full-text provided on Manchester Research Explorer is the Author Accepted Manuscript or Proof version this may differ from the final Published version. If citing, it is advised that you check and use the publisher's definitive version.

\section{General rights}

Copyright and moral rights for the publications made accessible in the Research Explorer are retained by the authors and/or other copyright owners and it is a condition of accessing publications that users recognise and abide by the legal requirements associated with these rights.

\section{Takedown policy}

If you believe that this document breaches copyright please refer to the University of Manchester's Takedown Procedures [http://man.ac.uk/04Y6Bo] or contact uml.scholarlycommunications@manchester.ac.uk providing relevant details, so we can investigate your claim.

\section{OPEN ACCESS}




\title{
An Understanding of Lattice Strain, Defects and Disorder in Nuclear Graphite
}

Ram Krishna ${ }^{a, \dagger}$, James Wade ${ }^{a}$, Abbie N Jones ${ }^{a}$, Michael Lasithiotakis ${ }^{a, b}$, Paul M. Mummery ${ }^{a}$, and Barry J. Marsden ${ }^{a}$

${ }^{a}$ Nuclear Graphite Research Group, School of Mechanical, Aerospace \& Civil Engineering, University of Manchester, Manchester, M13 9PL, UK

${ }^{b}$ Greek Atomic Energy Commission, Agia Paraskevi, 15310-Athens, Greece

\begin{abstract}
In this study, microstructural parameters, such as lattice dimension, micro-strain and dislocation density, of different neutron-irradiated graphite grades have been evaluated using the diffraction profiles of X-ray diffraction (XRD) and the scattering profiles of Raman spectroscopy. Using Gen-IV candidate graphite samples (grade PCEA, GrafTech), subjected to neutron irradiation at $900{ }^{\circ} \mathrm{C}$ to 6.6 and $10.2 \mathrm{dpa}$, and graphite samples of similar grain size and microstructure taken from the core of the British Experimental Pile Zero reactor, which have been irradiated at $100-120{ }^{\circ} \mathrm{C}$ to $1.60 \mathrm{dpa}$, an investigation on the effect of irradiation dose and temperature on the aforementioned microstructural parameters is presented. Coefficients of variation for the lateral crystallite size, micro-strain and dislocation density, as acquired from XRD and Raman spectroscopy, are at approximately 13\%, 17\% and $38 \%$, respectively. Quantification of microstructural parameters as a function of neutron dose from the two complementary techniques are in agreement and imply that the quantified results are reasonable. Supporting evidence for the microstructural information obtained is provided by direct observations made using high-resolution transmission electron microscopy. Damage mechanisms are reviewed and discussed in relation to results presented.
\end{abstract}

\footnotetext{
${ }^{\dagger}$ Corresponding author: Email: ram.krishna-2@manchester.ac.uk (Ram Krishna). Tel.: +44(0) 1613062352 .
} 
Keywords: Graphite; Neutron irradiation damage; X-ray diffraction; Raman spectroscopy; High-resolution transmission electron microscopy; Dislocation density; Micro-strain; Crystallite size.

\section{Introduction}

Since the early 1940s, graphite has been the material of choice for many nuclear reactors (operating temperature range from $100{ }^{\circ} \mathrm{C}$ to $400{ }^{\circ} \mathrm{C}$ ) owing to the materials excellent neutron moderation and reflection efficiencies, good machinability, cost effectiveness and high availability. Another principal advantage of graphite is the materials capacity to function as a supporting structure for the fuel/control rods and coolant gas flow channels necessary to sustain nuclear fission reactions [1, 2]. More recently, with the development of next generation nuclear reactors, such as high temperature and very high temperature reactors (HTR \& VHTRs), gas-cooled fast reactors (GFRs) and molten salt reactors (MSRs), interest in graphite has increased due to the materials excellent thermal and chemical stability. Given the continued international interest in graphite-moderated reactor cores, an essential requirement is to ensure that the lifetime of such reactors is not limited by the performance of the selected graphite grade [3]. A number of irradiation damage studies have shown that the initial degree of crystallinity and the crystallite size both play an important role in asymmetrical dimensional and anisotropic property changes induced by fast neutrons in graphite (altering the magnitude and configuration of internal stresses) $[4,5]$. Consequently, it is important to develop a comprehensive understanding of the change in microstructural behaviour and associated structural parameters that correlate with bulk material property changes under fast neutron irradiation conditions $[3,6]$.

Irradiation alters lattice parameters, causes graphite crystal lattice expansion in the $c$-axis and shrinkage in the $a$-axis, introduces dislocations and other defects, and generates micro-strains, all of which influence many of material properties of graphite (altering the graphite's capacity to endure the internal stresses present) $[4,7,8,9]$. However, despite this, very few in-depth microstructural studies have been conducted on irradiated graphite $[10,11,12,13$, $14,15,16,17]$. The majority of those that have been performed have employed highresolution transmission electron microscopy (HRTEM) to examine irradiation-induced defect formations $[15,16]$ and micro-crack evolution [18] in various nuclear graphite grades. This 
work looks to expand upon the current knowledge by examining the influence of irradiation dose and temperature on the bulk crystal structure of graphite. The radiation-induced changes to the microstructure are important for an accurate understanding of the stress-state of nuclear graphite during service. Therefore, in addition to assisting the life extension of the advanced gas-cooled reactors currently operating, the results of this work could also be pertinent in the appraisal of developmental graphite grades intended for future GEN IV high temperature reactors.

As stated above, HRTEM is a common and highly effective technique used to study defects in graphite crystal structure. The results of TEM are important in correlating with the asymmetrical microstructural changes observed in graphite after neutron irradiation $[15,16]$. However, the complexity of the technique, associated with electron beam damage and the introduction of additional dislocations during sample preparation, limits its suitability for routine application. In this respect, other more powerful experimental techniques that can be used to investigate the microstructural parameters are X-ray diffractometry and Raman spectroscopy, both of which provide data that can be analysed to obtain microstructural information of materials. Both the techniques are well established, non-destructive, have a practical significance and provide information on the bulk properties of polycrystalline materials averaged over the whole sample volume $(\sim 1 \mu \mathrm{m}$ below the top layer $)[19,20]$. Only a handful of literature is available that focuses on characterising the change in crystal dimensions and lattice parameters from the diffraction and spectroscopic data obtained via XRD and Raman spectroscopy, respectively $[10,11,12,13,14,21]$. Tuinstra and Koenig (1970) Cançado et al. (2006) and Lu et al. (2001), for example, have both performed systematic X-ray diffraction and Raman studies on graphitised samples [10, 22, 23]. However, literature sources report several X-ray line profile fitting procedures and a variety of XRD and Raman models that are underutilised in graphite. These methods are routinely used to quantitatively characterise the microstructural parameters of metallic and ceramic materials, including alloys with nuclear applications [24, 25].

In this study, two different graphite grades irradiated under different reactor operating conditions are characterised for microstructural evolution using XRD and Raman spectroscopy. The graphite grades examined are very similar in microstructure. One grade has been obtained from the core of the British Experimental Pile Zero reactor (BEPO), while the other one is a PCEA grade irradiated in the High Flux Isotope Reactor (HFIR) at Oak 
Ridge National Laboratory (ORNL), USA. For the latter neutron irradiation experiment, the mechanical, thermal and electrical properties changes displayed have been reported by Burchell and Strizak elsewhere [26]. Microstructural parameters of lattice disordering, crystallite size, micro-strain, and dislocation defect density are obtained from X-ray diffraction line profiles and compared with Raman spectrum analysis. These results are then judged against HRTEM observations of both sets of samples. The quantified values extracted from the measured diffraction data and Raman spectrums are then discussed in relation to the established damage mechanisms associated with neutron irradiation.

\section{Materials and Experimental Details}

\subsection{The Graphite Microstructure}

The graphite used in the nuclear industry is a synthetic product consisting of coke filler particles impregnated with a pitch binder phase (from a petroleum or coal tar source). Once graphitised at $\sim 3000{ }^{\circ} \mathrm{C}[2]$, the resultant microstructure is polycrystalline in nature and has a complex pore structure spanning across multiple scale lengths (micro, meso and macro pores). Both the filler and binder phases comprise of domains of aligned crystallites. Each crystallite contains parallel layer planes of near-perfect, hexagonally-arranged carbon atoms. During irradiation, these carbon atoms are displaced from their lattice sites, generating a variety of crystallographic defects, namely interstitial atoms and vacancies (Frenkel pairs). The formation of such defects, in turn, causes crystal expansion in the $c$-axis and shrinkage in the $a$-axis lattice parameters through basal dislocation interactions, the generation of microstrain and alterations to the mechanical, thermal and electrical properties of graphite.

\subsection{Low Irradiated, Low Temperature Graphite}

Graphite samples were sourced from the BEPO reactor at Harwell, Oxfordshire, UK, which operated up to 1968. BEPO was a $6 \mathrm{MW}$ graphite moderated reactor fuelled with natural uranium (later slightly enriched) and was primarily used for the production of radioisotopes, dosimetry and neutronic calculations for future reactors. The graphite used in this reactor core was sourced from Canada, referenced as AXGP. The reactor core graphite operated in air at coolant temperatures between $20-120{ }^{\circ} \mathrm{C}$. During operation the core was annealed twice to 
remove stored Wigner energy at $\sim 250{ }^{\circ} \mathrm{C}$. The BEPO graphite samples removed from the core centre have received a maximum dose of $1.60 \mathrm{dpa}$ (displacement per atoms) at an average fast flux of $6.2 \times 10^{10}$ neutrons $/ \mathrm{cm}^{2} / \mathrm{sec}[15,27]$.

\subsection{High Irradiated, High Temperature Graphite}

PCEA is an anisotropic, medium grain graphite grade (density $\sim 1.8 \mathrm{~g} / \mathrm{cm}^{3}$ ). Manufactured by GrafTech International Ltd. via an extrusion process, it contains petroleum coke as filler particles with a maximum size of $0.8 \mathrm{~mm}$ and is comparable in grain size and structure to BEPO [28]. These graphite where subjected to irradiation at temperatures of $\sim 900{ }^{\circ} \mathrm{C}$ to neutron doses of 6.6 and $10.2 \mathrm{dpa}$ in the HFIR at ORNL at an average fast flux of $3.0 \times 10^{14}$ neutrons $/ \mathrm{cm}^{2} / \mathrm{sec}(\mathrm{E}>50 \mathrm{keV})$.

Based on similar experimental observations, BEPO and PCEA graphite are very comparable in microstructure and filler particle (grain) size. This is shown in the polarised micrograph images in Figs. 1(a-b).

\subsection{X-Ray Diffraction}

Reflective X-ray diffraction patterns were recorded from a number of prepared graphite samples using an X-ray diffractometer (Rigaku SmartLab, Japan) with a $\mathrm{Cu} \mathrm{K} \alpha$ radiation source $(\lambda=1.54 \AA)$. The diffractometer operated at $40 \mathrm{kV}$ and $30 \mathrm{~mA}$. The diffraction profiles were obtained by varying the $2 \theta$ from $10^{\circ}$ to $90^{\circ}$ in a continuous scan mode with a step size of $0.01^{\circ}$. The conventional XRD patterns are the convolution of instrumental and microstructural effects that contribute to the line profile broadening. In order to analyse the diffraction line profile that is a direct result of the microstructural effects, a standard single crystal silicon sample was used to correct for instrumental broadening [29]. The microstructural effects responsible for the shape profile of the diffraction peaks (line broadening and shift) are the crystallite size distribution and the micro-strain within the crystallites introduced due to lattice defects. Here, the term 'crystallite size' may be referred to as the 'coherently scattering domain size'. 
In this study, a statistical-based modelling approach, the modified Rietveld technique, has been adopted for X-ray diffraction line profile analysis in order to obtain the microstructural information of the irradiated and non-irradiated samples [30, 31]. As part of this analysis, the experimental diffraction profiles were modelled using a pseudo-Voigt $(\mathrm{pV})$ shape function in the software program MAUD [32]. In accordance with the Rietveld method, fitting involved a non-linear least-squares refinement of deconvoluted theoretical line profiles until they matched a measured diffraction line profile [30]. According to the $p V$ function, the peak profile can be expressed as eq. (1), which is defined as a linear combination of Gaussian and Cauchy curves:

$$
p V(2 \theta)=\sum_{a_{1} a_{2}} I_{n t}(1-\eta)\left(1+S^{2}\right)^{-1}+\eta \exp \left(-\ln 2 \times S^{2}\right)
$$

where,

$$
S=\frac{\left(2 \theta-2 \theta_{0}\right)}{\beta} ; \theta_{0}
$$

where $S$ is the Bragg's angle corresponding to $\mathrm{K} \alpha$ radiation, $\beta$ is the full width at half maximum (FWHM), $\eta$ is the Gaussian component and $I_{n t}$ is the intensity parameter of the $p V$ function.

The fitted peak parameters were used to evaluate crystallite size and micro-strain in accordance with the Popa model of anisotropic size-strain broadening [33]. The shift, broadening and asymmetry experienced by line profiles due to the accumulation of irradiation defects was analysed using the Warren model [34]. Average dislocation densities $(\rho)$ were calculated from the relationship:

$$
\rho=\left(\rho_{D} \rho_{S}\right)^{\frac{1}{2}}
$$

where,

$$
\rho_{D}=\frac{3}{D_{a v}^{2}}
$$




$$
\rho_{S}=k \frac{<\varepsilon_{l}^{2}>}{\overline{b^{2}}}
$$

where $\rho_{D}$ is the dislocation density due to domain size, $\rho_{S}$ is the dislocation density due to micro-strain, $D_{a v}$ is the average domain size, $\varepsilon_{l}$ is the micro-strain with the domain, $k$ is a material constant and $\bar{b}$ is the Burgers vector [35]. As graphite is a hexagonal close packed (HCP) crystal structure, it has three slip systems: basal, prismatic and pyramidal. The directions, planes and Burgers vectors for these slip systems are given in Table 1. Despite having three slip systems available, theoretical and electron microscopy studies have shown that deformation in the graphite lattice during irradiation is dominated by basal and prismatic dislocation nucleation and glide/climb [7, 36]. Therefore, these two systems were the only ones considered in our analysis.

The interplanar spacing, $<d_{002}>$, was determined based on the two prominent $(00 l)$ lines, the Bragg reflections associated with basal layer stacking orders [37]. Given that $c=2 d_{002}$, the interplanar spacing was then used to determine the lattice parameters in the ' $c$ ' and ' $a$ ' axis using the following equation:

$$
\frac{1}{d^{2}}=\frac{4}{3}\left(\frac{h^{2}+h k+k^{2}}{a^{2}}\right)+\frac{l^{2}}{c^{2}}
$$

The degree of graphitisation, $\bar{g}$, for graphitisable carbons was also estimated from the interplanar spacing under the assumption that $<d_{002}>=0.356 \mathrm{~nm}$ for $\bar{g}=0$ [23], and $<d_{002}>$ $=0.3354 \mathrm{~nm}$ for $\bar{g}=1[38]$ :

$$
\bar{g}=\frac{0.356-d_{002}}{0.356-0.3354} \times 100
$$

The average lateral size, $L_{\mathrm{a}}$, and average stacking height, $L_{c}$, of the crystallites, as shown in Figs. 2(a-b), were estimated using the Scherrer equations [29]: 


$$
\begin{aligned}
& L_{c}=\frac{k \lambda}{\beta \cos \theta} \\
& L_{a}=\frac{1.84 \lambda}{\beta \cos \theta}
\end{aligned}
$$

where $k$ is the crystallite shape factor, which equates to 0.94 for polycrystalline graphite, $\beta$ is the FWHMs of the characteristic Bragg reflection peak, and $\theta$ is the corresponding scattering angles.

\subsection{Raman Mapping Area Spectroscopy}

Maps of the Raman vibrational spectra acquired from the irradiated and unirradiated graphite specimens were obtained using a Renishaw inVia spectrometer equipped with a $514.5 \mathrm{~nm}, 20$ $\mathrm{mW}$ argon laser with an excitation energy of $2.41 \mathrm{eV}$. A $\times 20$ objective lens was used to focus the laser beam, giving an approximate beam diameter of $1 \mu \mathrm{m}$ and a scan depth of $\sim 60 \mathrm{~nm}$ at the graphite surface. Highly ordered pyrolytic graphite (HOPG) was used as a reference $(G \sim$ $1580 \mathrm{~cm}^{-1}$ ) for spectral axis calibration. The zero position of the laser line and the Raman Gline position were aligned prior to the data collection of each sample. All spectra obtained from the Ramanscope were accurate to within $\pm 1 \mathrm{~cm}^{-1}$. Scans were performed in lines consisting of 10 points measurement. The acquisition time for each individual point scan was $10 \mathrm{~s}$. The line scans were made in consecutive rows to form a grid covering a sample area of $350 \times 250 \mu \mathrm{m}$. The total number of data points collected for each graphite sample was between 80 and 100. Processing of the collected data was later completed using LabSpec 6 software.

Raman peak profile analysis was used to calculate the characteristic crystallite size [22], compressive residual stress [19] and dislocation density [39] across sub-surface regions of the graphite samples. Further details on the models used in these calculations can be found elsewhere $[19,22,39,40]$. The crystallite size was determined based on the integrated area ratio between the $\mathrm{D}$ and $\mathrm{G}$ peak intensities, termed $I_{D}$ and $I_{G}$ respectively, using the following equation: 


$$
L_{a}(n m)=2.4 \times 10^{-10} \lambda^{4}\left(\frac{I_{D}}{I_{G}}\right)^{-1}
$$

where $\lambda$ is the laser wavelength in $\mathrm{nm}$. Compressive residual stresses were estimated based on the shift of the Raman G-peak. The surface stress state is calculated by inputting the Raman G-line shift into the following functions:

$$
\begin{aligned}
& \sigma_{x}(M P a)=0.2019 \Delta \omega\left(\mathrm{cm}^{-1}\right) \\
& \sigma_{y}(M P a)=0.0749 \Delta \omega\left(\mathrm{cm}^{-1}\right)
\end{aligned}
$$

where $\Delta \omega$ is the Raman shift in $\mathrm{cm}^{-1}$ and $\sigma_{x}$ and $\sigma_{y}$ are compressive residual stresses along $x$ and $y$-directions in MPa. It has been reported that the broadening of the Raman G-line in irradiated graphite corresponds with the dislocation population over the scanned volume and results from the strain field around dislocations [41]. In order to quantify the number of preexisting dislocations and those introduced during irradiation based on the broadening of the Raman G-peak, the model of $\mathrm{Wu}$ et al. (2008) was adopted [39]. In this model, dislocation densities can be estimated based on the broadening of a characteristic peak in a spectroscopic line profile following the function:

$$
\sqrt{\Delta \mu^{2}}=K F(\rho)
$$

where,

$$
K=\frac{G b}{2 \sqrt{2 \pi}(1-v)}\left\{\left(5+12 v+2 v^{2}\right) \Pi_{a}^{2}+2(1+2 v) \Pi_{a} \Pi_{c}+\Pi_{c}^{2}\right\}^{\frac{1}{2}}
$$

and,

$$
F(\rho)=\sqrt{\rho \ln (1 / b \sqrt{\pi \rho})}
$$


where $\Delta \mu$ is the difference in the FWHM between the graphite sample and the reference sample, $\rho$ is the dislocation density measured in $\mathrm{m}^{-2}, G$ is the shear modulus, $v$ is Poisson's ratio, and $\Pi_{a}$ and $\Pi_{c}$ are the piezo-spectroscopic coefficients. HOPG was used as the standard reference material for these experiments as it is assumed to be free from crystal strain and, therefore, should contain negligible pre-existing dislocations. For simplicity, the model above assumes that all dislocations are of edge character and lie in all existing basal planes. This assumption is consistent with the literature, where, despite non-basal dislocations existing in the graphite, the majority of dislocations observed are basal dislocations [7, 41].

The inputs required for the model of $\mathrm{Wu}$ et al. (2008) and used to estimate dislocation densities in PCEA and BEPO are as follows; shear modulus, $\mathrm{G}=4.5 \mathrm{GPa}$ (with grain, WG) and 3.3 GPa (against grain, AG); Poisson's ratio, $v=0.23(\mathrm{WG})$ and $0.16(\mathrm{AG})$; the modulus of Burgers vector, $|\bar{b}|=0.116 \mathrm{~nm}$ for the Burgers vector $\bar{b}=\frac{a}{3}<1 \overline{12} 0>$, (basal edge dislocations, parallel to basal planes) where $a=0.247 \mathrm{~nm}$ and the modulus of Burgers vector, $|\bar{b}|=0.3354 \mathrm{~nm}$ for the Burgers vector $\bar{b}=\frac{c}{2}\langle 0001\rangle$ (partial prismatic edge dislocation, perpendicular to basal layers) where $c=0.667 \mathrm{~nm}$ [42]. The piezo-spectroscopic coefficients required for the model are taken from the reference [43] and derived from stress sensitivity experiments in two-dimensional carbon materials using the Raman G-peak: $\Pi_{a}=3.5 \mathrm{~cm}^{-}$ ${ }^{1} \mathrm{GPa}^{-1}, \Pi_{c}=1.6 \mathrm{~cm}^{-1} \mathrm{GPa}^{-1}$.

Figure 3 shows that in using the property values listed above, a reasonable dislocation density can be estimated based on the Raman G-peak broadening. The simulated results show a smooth, non-linear relationship between Raman G-peak broadening and dislocation density. This is in agreement with the original work of $\mathrm{Wu}$ et al. In addition, dislocation densities do not appear to saturate at high G-peak broadenings in graphite.

\subsection{High-Resolution Transmission Electron Microscopy}

Thin foil samples for TEM were prepared from the bulk graphite using a FEI Quanta 3D FEG SEM/FIB. Using a gallium ion beam energy of $5 \mathrm{kV}$ and a beam current around $0.03 \mathrm{nA}$, specimens $150-200 \mathrm{~nm}$ thick were produced. In order to minimise any potential beam damage 
and/or re-deposition of sputtered material, thinning of the samples was done at $2 \mathrm{kV}$ and a current of $5 \mathrm{pA}$.

HRTEM imaging was conducted using Joel 2010F TEM operating at an accelerating voltage of $200 \mathrm{kV}$. While operating electron microscope at such a high $\mathrm{kV}$, extra care was taken to avoid electron damage to the site of interest. To enhance the weak lattice image information a filtering technique has been adopted from a similar approach employed in previous studies $[18,44,45]$.

\section{Results and Discussion}

\subsection{X-Ray Diffraction Analysis of PCEA and BEPO Graphite}

Figure 4(a-c) shows the XRD patterns of virgin and irradiated PCEA. Residual plots for each XRD profile have also been provided. The major Bragg peaks in graphite correspond to the (002), (100), (101), (004), (110) and (112) reflections. These were used to estimate the microstructural information in Table 2. Note, no new reflections were observed. The XRD patterns of the virgin PCEA graphite display sharp, slender and intense Bragg peaks compared to the irradiated graphite samples in Figs. $4 \mathrm{~b}$ and $4 \mathrm{c}$. In the irradiated PCEA, the displacement of carbon atoms during irradiation leads to a reduction in intensity, shifting and broadening of the Bragg peaks, corresponding with an increase in lattice disordering, interactions between dislocations and micro-strain in the structure. With such modifications to the shape of the Bragg peaks, the correlation between the pattern of the predicted $p V$ peaks and the pattern of the actual peaks has decreased, as indicated by the wider fluctuations in the residual plots with increasing irradiation dose.

The XRD profile for the irradiated BEPO graphite is displayed in Fig. 5. The same Bragg peaks of the (002), (100), (101), (004), (110) and (112) reflections are also identified in this sample. All peaks show appreciable broadening. Possible contributions to this include the poor graphitisation of BEPO during manufacture and/or the samples exposure to fast-neutron irradiation, which has led to less crystalline/disordered graphite structure. 
In accordance with the microstructural information given in Table 2 derived from the XRD peak profile parameters, irradiation of PCEA graphite increases the interplanar $\left\langle d_{002}\right\rangle$ spacing showing an expansion of $0.34 \%$ and $0.47 \%$ at 6.6 and $10.2 d p a$, respectively. By comparing the $<d_{002}>$ value of the irradiated BEPO graphite with that of the virgin PCEA, it is apparent that the BEPO has experienced the highest degree of expansion, at $3.51 \%$ after irradiation to $1.60 \mathrm{dpa}$. Given that the $<d_{002}>$ is equivalent to $\frac{c}{2}$, expansion of the interplanar spacing also means that the lattice parameter $c$ has increased proportionally with neutron irradiation. Conversely, values for the lattice parameter $a$ reduce by $0.52 \%$ and $1 \%$ for the PCEA samples irradiated to 6.6 and $10.2 \mathrm{dpa}$, respectively, with the smallest reduction of $0.37 \%$ being in the BEPO graphite irradiated to $1.60 \mathrm{dpa}$. A rapid decrease in stacking height, $L_{c}$, is also registered from $33.34 \mathrm{~nm}$ to $9.17 \mathrm{~nm}$ for PCEA irradiated to $10.2 \mathrm{dpa}$ and 13.75 $\mathrm{nm}$ for BEPO graphite irradiated to $1.60 \mathrm{dpa}$. A similar trend is also observed for the crystallite lateral size, $L_{a}$, a decrease from $36.56 \mathrm{~nm}$ to $11.17 \mathrm{~nm}$ for PCEA irradiated to 10.2 $d p a$ and $14.14 \mathrm{~nm}$ for BEPO graphite irradiated to $1.60 \mathrm{dpa}$. A graphical depiction of the change in lattice dimension $\left(\frac{\Delta c}{c} \%\right.$ and $\left.\frac{\Delta a}{a} \%\right)$, stacking height and lateral size in irradiated BEPO and PCEA graphite is given in Fig. 6. From Fig. 6 it is clear that the magnitude of the aforementioned changes is highly dependent on the irradiation dose and temperature.

Other important microstructural parameters extracted from the diffraction line profile analysis are listed in Table 3 and presented in Fig. 7. Based on these results, significant changes in average crystallite size, dislocation density and micro-strain in irradiated PCEA and BEPO as compared to the virgin PCEA graphite are found. Averaged dislocation density calculations show an increase in dislocation density by two orders of magnitude in the irradiated PCEA samples and three orders of magnitude in BEPO graphite. By comparison, the increases in micro-strain are less, but still substantial at 6 times in PCEA and 10 times in BEPO graphite compared to virgin PCEA.

\subsection{Raman Spectra Analysis for PCEA and BEPO Graphite}

Figure 8(a-b) shows the Raman spectra for virgin and irradiated PCEA and irradiated BEPO graphite, denoting the Raman G-peak positions and FWHMs. These Raman spectra have been analysed in order to quantify the crystallite lateral size, micro-strain and dislocation 
densities for each sample, the details of which are listed in Table 4. The intensity, wavenumber shift and broadening of the G-peak profile at $\sim 1582 \mathrm{~cm}^{-1}$ in each spectra show a rapid change with increasing radiation dose. This indicates a decrease in $s p^{2}$-hybridised hexagonal carbon networks with neutron exposure. The D-peak intensity at $\sim 1351 \mathrm{~cm}^{-1}$ also increases considerably with increasing radiation dose, confirming the introduction of irradiation-induced in-plane defects in the layered structure. A reduction of intensity and asymmetrical broadening of the peaks present at higher wavenumbers $\left(>2500 \mathrm{~cm}^{-1}\right)$ also suggests bending and tilting of basal layers. In the Raman spectra for the $10.2 \mathrm{dpa}$ PCEA graphite and the BEPO graphite, these higher wavenumber peaks are weak, but still resolvable, and confirm that the original graphitic structure is still maintained in these graphites, even after high neutron exposure.

As shown in Table 4, the structural parameter measurements derived from Raman spectra analysis produce trends similar to those measured by XRD. The crystallite lateral size decreases from $40.61 \mathrm{~nm}$ to $11.94 \mathrm{~nm}$ for PCEA irradiated to $10.2 \mathrm{dpa}$ and to $18.21 \mathrm{~nm}$ for BEPO graphite irradiated to $1.60 \mathrm{dpa}$. The micro-strain in the lattice increases with dose from $0.18 \%$ to $0.86 \%$ for PCEA irradiated to $10.2 d p a$ and to $1.88 \%$ for BEPO graphite. Dislocation density estimations also show the same increase of two orders of magnitude in the irradiated PCEA samples and three orders of magnitude in BEPO graphite. A direct comparison of these results is presented in the discussion below.

\subsection{High-Resolution Transmission Electron Microscopy}

A HRTEM image depicting the crystal lattice of virgin PCEA is displayed in Fig. 9(a) together with a post-processed image of the same lattice after noise-filtration in Fig. 9(b). A comparison of both Fig. 9(a) and (b) shows that the noise-filtered image in Fig. 9(b) is of superior clarity and provides improved definition of the individual basal layers depicted in both images. This is achieved in the filtered images without masking the appearance of lattice defects. The boxes on the lattice image show prismatic edge dislocations in virgin graphite. The density of these dislocations increases in the irradiated BEPO and PCEA graphite, as confirmed in the magnified and processed HRTEM images in Figs. 10(a-c). Despite less exposure to fast-neutron irradiation, it is apparent that the BEPO graphite contains the highest amount of damage, characterised by mostly basal, non-basal and prismatic dislocations as well as what appear to be interlayer defects, see Fig. 11(a). Meanwhile, high temperature 
irradiation damage in the PCEA graphite increases as a function of irradiation dose, the irradiated PCEA at 10.2 $\mathrm{dpa}$ having the most defects followed by the irradiated PCEA at 6.6 $d p a$ and then the virgin PCEA.

\section{Discussion}

\subsection{XRD vs. Raman Analysis}

As shown in Figs. 12(a-c), a comparison of the average values estimated for the crystallite size, lattice micro-strain, and dislocation density show that the quantified results obtained by both XRD and Raman spectral analysis are well-aligned with one another. Calculations of the coefficient of variation reveal the limits of variability to be approximately $13 \%, 17 \%$ and $38 \%$, respectively. In reviewing the individual data points, the virgin PCEA graphite exhibits the lowest differences between the Raman and XRD derived values. This gradually changes in the irradiated PCEA and BEPO graphites where larger disparities are found in the values extracted from the samples exposed to higher irradiation doses and lower temperatures. Such a trend is particularly evident in for the micro-strain and dislocation density measurements presented in Fig. 12(b) and Fig. 12(c), respectively. In the PCEA graphite, the divergent behaviour becomes more apparent with increasing irradiation dose. Yet, the most significant differences are seen in the irradiated BEPO graphite that received the lowest irradiation dose. Therefore, the growing disparity between Raman and XRD derived values cannot simply be the result of an increased exposure to fast-neutron irradiation. Instead, a possible explanation may be found by analysing the HRTEM images in Figs. 9(a-b) and 10(a-c). Here, the most severe lattice damage is in the BEPO graphite, likely owing to the sub-300 ${ }^{\circ} \mathrm{C}$ temperatures experienced during irradiation [46]. The next most severely damaged specimen is the irradiated PCEA at $10.2 d p a$ followed by the irradiated PCEA at $6.6 d p a$ and then the virgin PCEA. This trend is consistent with the differences displayed by the Raman and XRD derived values in Figs. 12(a-c) and would suggest that such changes are dependent on the increasing defect damage sustained during irradiation by the different graphite grades. This is influenced by the irradiation temperature as well as the irradiation dose.

Based on such a finding and the fact that the Raman spectral analysis always produces the higher values, it is likely that the increasing disparity between Raman and XRD derived 
values is the result of Raman spectroscopy's capacity to detect smaller shifts in interatomic vibrational frequency caused by the stress-induced changes in strain due to the presence of irradiation defects. An improved cohesion in the data may be found by using more sensitive X-ray synchrotron facilities instead of the laboratory scale XRD equipment used for this work. Nevertheless, these findings demonstrate that both techniques are complementary to each other and are highly sensitive to small changes in the crystal structure. As well as validating the data acquired from either technique, the results in Figs. 12(a-c) are confirmation that the models employed throughout this paper are robust and, despite having a foundation with metal or ceramic materials, can be applied to graphite with confidence.

\subsection{Effect of Dose on the Lattice Parameters}

Both the XRD and Raman spectroscopy results indicate progressive deterioration of the PCEA graphite lattice with increasing fast-neutron irradiation dose, corresponding to an increase in interplanar spacing, a reduction in crystallite size and an overall loss of crystallinity. The principle damage mechanism associated with the aforementioned microstructural changes is well-understood and described in detail elsewhere [7]. Briefly though, the microstructural evolution of graphite during irradiation is driven by displacement damage cascades. The sequence of events for such a process is as follows:

1. An initial collision between a fast-neutron, with a kinetic energy of 1-2 MeV, and a carbon atom displaces it, generating a primary knock-on atom (PKA).

2. The kinetic energy transferred to this PKA is then released through a number of successive collisions with secondary carbon atoms.

3. If the kinetic energy of the PKA is above the critical displacement energy required to displace a carbon atom from its lattice site (20-60 eV [47]), then displacement of the secondary carbon atoms will occur (SKA).

4. Further collisions between SKAs and other carbon atoms results in this cascade of displacement damage until the energy of the collisions falls to $\sim 100 \mathrm{eV}$, at which point the displacement of carbon atoms becomes so short-ranged that they immediately recombine with their vacant lattice sites.

The predominant outcome of a single collision cascade is the creation of interstitial atoms and vacancies, referred to as Frenkel pairs. It is the accumulation of these Frenkel pairs that leads 
to the aforementioned microstructural changes. As confirmed in Figs. 12(b-c), for the PCEA samples, the accumulation of such defects is solely dependent on irradiation dose. At higher concentrations, the generation of these point defects increasingly affects the lattice periodicity of the hexagonally-arranged crystal structure of pristine graphite, which, as shown in Fig. 12(b), leads to an increase in internal strain. The filtered HRTEM images in Figs. 9(b) and 10(b-c) demonstrate such a change in the PCEA specimens with increasing dose. The basal layers in the virgin PCEA display long-range order. The crystallite imperfections that are present are limited and the result of the poor graphitability of the carbonised products prior to graphitisation and/or the adoption of non-optimal graphitisation conditions (i.e. exclusion of oxygen and at temperatures $\geq 3000{ }^{\circ} \mathrm{C}$ ). With exposure to fast-neutron irradiation, the basal planes of the irradiated PCEA specimens begin to display higher concentrations of crystal defects, mainly basal dislocations. This is particularly evident in the PCEA specimen irradiated to $6.6 \mathrm{dpa}$, which exhibit regions of near perfect basal layers surrounded by "pockets" of higher disorder. In the PCEA specimen irradiated to $10.2 \mathrm{dpa}$, the more homogenous distribution and higher concentration of crystallographic defects means that these pockets are less noticeable, however the graphitic structure remains prominent. It is the introduction of such disorder that leads to the reduced crystallinity of the PCEA specimens with increasing irradiation dose, as indicated by the decrease in the degree of graphitisation from $87.47 \%$ in the virgin PCEA to $79.81 \%$ in PCEA graphite irradiated to $10.2 \mathrm{dpa}$, see Table 2. With continued exposure to even higher irradiation doses, full amorphisation of the graphitic structure of the PCEA specimens is to be expected.

Simultaneous to the disordering of the stacked structure is the expansion of the interplanar $<d_{002}>$ spacing or $c$-axis (equal to $2 d_{002}$ ) and shrinkage in the lateral direction or $a$-axis. The standard model adopted to explain this occurrence, irrespective of irradiation temperature or dose, was originally proposed by Kelly et al. and involves the aggregation of displaced interstitial carbon atoms to form additional basal layers [48]. In response to this, the preexisting basal planes open in order to accommodate the new interstitial atomic planes and their associated defects i.e. spiro-interstitials, di-vacancies, etc. The coinciding shrinkage parallel to the layer plane is then the result of vacancy lines that collapse. However, recent works by Heggie and co-workers have questioned this concept [46], stating that: (1) interstitials are immobile at low temperatures and cannot aggregate to form new graphene sheets i.e. the standard model is inadequate for neutron irradiation at $<250{ }^{\circ} \mathrm{C}$; (2) the small 
interstitial defect clusters that would form are unable to substantially affect the interlayer spacing; (3) the standard model fails to account for the nucleation and movement of basal dislocations, which X-ray diffraction experiments indicate are dominant processes during neutron irradiation. Consequently, Heggie suggests that the combination of interlayer defects (i.e. spiro-interstitials, di-interstitials and interplanar divacancies), which pin the graphene layers in place, and the accumulation of Frenkel pairs, leads to the build-up of stress and the eventual buckling/wrinkling of the graphitic planes. It is this buckling/wrinkling that causes the expansion in the $c$-axis at irradiation temperatures of $<250{ }^{\circ} \mathrm{C}$. At irradiation temperatures $>250{ }^{\circ} \mathrm{C}$, such interlayer defects disappear and the buckling/wrinkling of the graphite layers is replaced by the folding of the planes to form "ruck and tuck" defects. Close examination of the HRTEM images of the PCEA graphite shows some evidence in support of both models. The green symbols in Figs. 11(b-c), for example, highlight multiple incidences of an incomplete plane like those described by Kelly et al. Unfortunately, observations of these images are unable to deduce how these planes have evolved into existence. This is important. A recent TEM study has shown that these planes can form as a result of an interstitial loop or prismatic dislocation [44]. However, the same study also shows an interstitial plane that nucleates in a way that is consistent with the interstitial aggregation and cluster model of Kelly et al. In addition to the aforementioned half-planes, further observations highlight signs of the buckling/wrinkling described by Heggie et al. in the graphite planes that make up the disordered sites of the irradiated PCEA specimens. This is particularly prominent in the HRTEM images of the PCEA graphite irradiated to $10.2 \mathrm{dpa}$. It is worth noting also that the amplitude of such planar fluctuations are even greater in the irradiated BEPO graphite; see Fig. 10(a). In accordance with Heggie's model, this is likely owing to the sub- $250{ }^{\circ} \mathrm{C}$ temperature at which the BEPO graphite was irradiated.

The final irradiation-induced microstructural change reported in the XRD and Raman spectroscopy results is a reduction in crystallite size; see Fig. 12(a). This has traditionally been associated with strain-induced bending and breaking of crystal planes during irradiation. However, given that the undulations observed in the graphitic planes of the irradiated PCEA samples in Figs. 10(b-c) are rather moderate in height and recent evidence showing that even multiple stacked graphene sheets can Z-shape fold in on themselves without breaking [49], such a mechanism seems inadequate as an explanation for the reduction in crystallite size observed in these irradiated graphite specimens. In addition, if one is to accept Heggie's 
"ruck and tuck" defect model, than the breaking of planes due to strain-induced bending is an incompatible concept. Whilst it is true that the lattice distortion may lead to broadening of the XRD (002) peak and the Raman G-peaks in Figs. 4(a-c) and 8(a), this has no physical meaning as far as a reduction in crystallite size [2]. In closely examining the HRTEM images in Figs. 9(b) and 10(b-c), we would conclude that the reduction in crystallite size that occurs with irradiation is a direct result of the expanding "pockets" of disorder that disrupt the regions of pristine graphite. It is the average size of these pristine areas that will make up the majority of the crystallite size measurement. Meanwhile, the defined edges of the disordered regions are where the crystal misalignment, commonly associated with a grain boundary in metallic and ceramic materials, begins. As described in detail elsewhere [50], with continual neutron damage, these disordered areas diminish in number, but the total amount of disorder increases, percolating across the entire graphite microstructure. As the disordered pockets collapse to form amorphous graphite, only remnants of the pristine graphene layers are retained. A comparison of the virgin and irradiated PCEA samples in Figs. 9(b) and 10(b-c) provides a glimpse of this progressive process, showing a transition from easily distinguishable regions of pristine graphite to an almost exclusively disordered microstructure in which areas of pristine graphite are difficult to resolve.

\subsection{Effect of Temperature on the Lattice Parameters}

In reviewing the data presented for the BEPO graphite, it is apparent that the microstructural damage that leads to variations in the lattice parameters is influenced by irradiation temperature as well as irradiation dose. This is particularly noticeable in the HRTEM images in Figs. 10(a-c), where the BEPO graphite shows the most severe defect damage despite receiving the lowest irradiation dose of just $1.6 \mathrm{dpa}$. The current understanding of the effect of temperature during irradiation is that at high temperatures there is a simultaneous "annealing" process that competes with the continual introduction of neutron damage cascades [7]. This annealing process involves the recombination or "annihilation" of the interstitial atoms and vacancies that are created during irradiation. Essentially, higher irradiation temperatures raise the threshold energy for an atomic displacement, $E_{d}$, as the interstitial-vacancy separation distance required to generate a stable Frenkel-pair is increased. At low irradiation temperatures $\left(<250-300^{\circ} \mathrm{C}\right), E_{d}$ remains low and any annealing of the neutron damage introduced is restricted. Therefore, by comparison, the rate of Frenkel pair 
accumulation is much faster and much higher defect densities are retained at much lower doses. Confirmation of this can be found in Fig. 12(c), where the BEPO graphite irradiated to just 1.6 dpa has an estimated dislocation density that is three orders of magnitude higher than virgin PCEA and one order of magnitude higher than PCEA irradiated to 10.2 dpa. In retaining such a high number of defects, the irradiated BEPO graphite invariably has the lowest degree of graphitisation/crystallinity of all the graphites tested at $29.9 \%$ and the highest levels of lattice strain, as indicated in Table 2 and Fig. 12(b) respectively. The impact this high lattice strain has on the microstructure can be seen by comparing the crystalline dimensional change values given in Fig. 6, where the net lattice volume expansion exhibited by the BEPO graphite irradiated at $100-120{ }^{\circ} \mathrm{C}$ is in direct contrast to the net shrinkage observed in both the PCEA specimens irradiated at $900{ }^{\circ} \mathrm{C}$. Both of these responses are typical [53] and commonly explained based on the premise that variations in irradiation temperature influence the mobility of vacancies. As mentioned above, in-plane or $a$-axis shrinkage of the graphitic layers is facilitated by the coalescence of vacancies to form vacancy lines and large vacancy clusters [48]. At a critical size these defects collapse, causing contraction parallel to the layer plane. At high temperatures, vacancies are mobile (as are interstitials) and can migrate to form many of these vacancy structures, promoting more lateral shrinkage [7]. Conversely, at low temperatures, vacancies are immobile and tend to remain as non-collapsible single point defects within the lattice [51]. Given the lack of $a$-axis shrinkage, there is nothing to counteract the $c$-axis expansion that continuous to occur. Consequently, the $c$-axis expansion ends up dominating crystallite dimensional change, resulting in net lattice volume expansion in graphites irradiated at low temperatures.

\section{Conclusion}

XRD, Raman spectroscopy and HRTEM has been used to observe and quantify the effects of irradiation-induced damage on two nuclear grade graphites irradiated at different temperatures. A comparison of the microstructural information extracted from the peak profiles of both XRD and Raman spectroscopy has shown that both techniques produce agreeable results for the graphite crystallite size, lattice micro-strain and dislocation density. Analysis of the microstructural parameters of the virgin PCEA and the two PCEA samples irradiated to $6.6 \mathrm{dpa}$ and $10.2 \mathrm{dpa}$ has confirmed that higher irradiation doses result in higher dislocation defect densities, greater levels of lattice micro-strain and a reduced crystallite 
size. The aforementioned changes to the microstructural parameters have been associated with an increase in the total number atomic displacements that are allowed to take place during longer exposures to fast-neutron irradiation. A comparison of these results with those of the BEPO graphite irradiated at lower temperatures revealed similar findings. However, here the higher dislocation defect densities, greater levels of lattice micro-strain and a reduced crystallite size have been linked with a reduction in the threshold energy required to generate a stable atomic displacement, limiting the number of interstitial atoms and vacancies that recombine in the irradiated BEPO. In both incidences, a reduction in crystallite size has been attributed to the expansion of randomly-distributed, disordered pockets that break up the pristine graphite sheets. All of these conclusions are supported by the theories and atomistic simulations of low and high temperature irradiation and correspond well with established neutron irradiation damage mechanisms.

\section{Acknowledgements}

We gratefully acknowledge the support of the UKAEA, NDA and Oak Ridge National Laboratory, USA in supplying irradiated graphite samples. We would also like to acknowledge the financial support from Innovate UK and thank Prof Gareth Neighbour (Birmingham City University, UK) for the helpful discussions and comments given regarding this research.

\section{References}

[1] Fermi E. Experimental production of a divergent chain reaction. American Journal of Physics. 1952;20(9):536-58.

[2] Nightingale RE. Nuclear Graphite: Academic Press Inc, New York 1962.

[3] Marsden BJ, Hall GN. 4.11 - Graphite in Gas-Cooled Reactors A2 - Konings, Rudy J.M. Comprehensive Nuclear Materials. Oxford: Elsevier 2012:325-90.

[4] Kelly BT, Burchell TD. Structure-related property changes in polycrystalline graphite under neutron irradiation. Carbon. 1994;32(3):499-505.

[5] Brocklehurst JE, Kelly BT. The dimensional changes of highly-oriented pyrolytic graphite irradiated with fast neutrons at $430^{\circ} \mathrm{C}$ and $600^{\circ} \mathrm{C}$. Carbon. 1993;31(1):179-83. 
[6] Bonal J-P, Kohyama A, van der Laan J, Snead LL. Graphite, Ceramics, and Ceramic Composites for High-Temperature Nuclear Power Systems. MRS Bulletin. 2009;34(01):2834.

[7] Telling RH, Heggie MI. Radiation defects in graphite. Philosophical Magazine. 2007;87(31):4797-846.

[8] Shtrombakh YI, Gurovich BA, Platonov PA, Alekseev VM. Radiation damage of graphite and carbon-graphite materials. Journal of Nuclear Materials. 1995;225:273-301.

[9] Burchell TD. A microstructurally based fracture model for polygranular graphites. Carbon. 1996;34(3):297-316.

[10] Tuinstra F, Koenig JL. Raman spectrum of graphite. The Journal of Chemical Physics. 1970;53(3):1126-30.

[11] Bacon GE, Warren BE. X-ray diffraction studies of neutron-irradiated graphite. Acta Crystallographica. 1956;9:1029-35.

[12] Asthana A, Matsui Y, Yasuda M, Kimoto K, Iwata T, Ohshima K-i. Investigations on the structural disordering of neutron-irradiated highly oriented pyrolytic graphite by X-ray diffraction and electron microscopy. Journal of Applied Crystallography. 2005;38(2):361-7.

[13] Eeles W. Diffuse diffraction phenomena from neutron-irradiated graphite single crystals. Acta Crystallographica Section A. 1968;24(6):688-9.

[14] Niwase K. Irradiation-induced amorphization of graphite: A dislocation accumulation model. Philosophical Magazine Letters. 2002;82(7):401-8.

[15] Krishna R, Jones AN, McDermott L, Marsden BJ. Neutron irradiation damage of nuclear graphite studied by high-resolution transmission electron microscopy and Raman spectroscopy. Journal of Nuclear Materials. 2015;467(2):557-65.

[16] Karthik C, Kane J, Butt DP, Windes WE, Ubic R. Neutron irradiation induced microstructural changes in NBG-18 and IG-110 nuclear graphites. Carbon. 2015;86:124-31.

[17] Zheng G, Xu P, Sridharan K, Allen T. Characterization of structural defects in nuclear graphite IG-110 and NBG-18. Journal of Nuclear Materials. 2014;446(1-3):193-9.

[18] Freeman HM, Jones AN, Ward MB, Hage FS, Tzelepi N, Ramasse QM, Scott AJ, Brydson, RMD. On the nature of cracks and voids in nuclear graphite. Carbon. 2016;103:4555.

[19] Krishna R, Jones AN, Edge R, Marsden BJ. Residual stress measurements in polycrystalline graphite with micro-Raman spectroscopy. Radiation Physics and Chemistry. 2015;111:14-23. 
[20] Iwashita N, Park CR, Fujimoto H, Shiraishi M, Inagaki M. Specification for a standard procedure of X-ray diffraction measurements on carbon materials. Carbon. 2004;42(4):70114.

[21] Tanabe T, Muto S, Gotoh Y, Niwase K. Reduction of the crystalline size of graphite by neutron irradiation. Journal of Nuclear Materials. 1990;175(3):258-61.

[22] Cançado LG, Takai K, Enoki T, Endo M, Kim YA, Mizusaki H, Jorio A, Coelho LN, Magalhäes-Paniago R, Pimenta MA. General equation for the determination of the crystallite size La of nanographite by Raman spectroscopy. Applied Physics Letters. 2006;88(16):163106.

[23] Lu L, Sahajwalla V, Kong C, Harris D. Quantitative X-ray diffraction analysis and its application to various coals. Carbon. 2001;39(12):1821-33.

[24] Neogy S, Mukherjee P, Srivastava AP, Singh MN, Gayathri N, Sinha AK, Srivastava D, Dey GK. Proton irradiation of $\mathrm{Zr}-1$ wt.\% Nb cladding material: A depth-wise assessment of inhomogeneous microstructural damage using X-ray diffraction line profile analyses. Journal of Alloys and Compounds. 2015;640:175-82.

[25] Béchade JL, Menut D, Doriot S, Schlutig S, Sitaud B. X-ray diffraction analysis of secondary phases in zirconium alloys before and after neutron irradiation at the MARS synchrotron radiation beamline. Journal of Nuclear Materials. 2013;437(1-3):365-72.

[26] Burchell TD, Strizak JP. The effect of neutron irradiation on the fracture toughness of graphite. Nuclear Engineering and Design. 2014;271:262-9.

[27] Wickham AJ. Diposition of Graphite Samples from BEPO as Supplied to NIREX; 2007.

[28] Jones AN, Hall GN, Joyce M, Hodgkins A, Wen K, Marrow TJ, Marsden BJ. Microstructural characterisation of nuclear grade graphite. Journal of Nuclear Materials. 2008;381(1-2):152-7.

[29] Seehra MS, Pavlovic AS. X-Ray diffraction, thermal expansion, electrical conductivity, and optical microscopy studies of coal-based graphites. Carbon. 1993;31(4):557-64.

[30] Lutterotti L, Scardi P. Simultaneous structure and size-strain refinement by the Rietveld method. Journal of Applied Crystallography. 1990;23(4):246-52.

[31] Albinati A, Willis BTM. The Rietveld method in neutron and X-ray powder diffraction. Journal of Applied Crystallography. 1982;15(4):361-74.

[32] Lutterotti L. Maud version 2.33. <maudradiographemacom $>2011$. 
[33] Popa N. The (hkl) Dependence of diffraction-line broadening caused by strain and size for all Laue groups in Rietveld refinement. Journal of Applied Crystallography. 1998;31(2):176-80.

[34] Warren BE. X-ray Diffraction: Dover Publications Inc, New York 1990.

[35] Williamson GK, Smallman RE. III. Dislocation densities in some annealed and coldworked metals from measurements on the X-ray Debye-Scherrer spectrum. Philosophical Magazine. 1956;1(1):34-46.

[36] Telling RH, Heggie MI. Stacking fault and dislocation glide on the basal plane of graphite. Philosophical Magazine Letters. 2003;83(7):411-21.

[37] Takagi H, Maruyama K, Yoshizawa N, Yamada Y, Sato Y. XRD analysis of carbon stacking structure in coal during heat treatment. Fuel. 2004;83(17-18):2427-33.

[38] Houska CR, Warren BE. X-Ray study of the graphitization of carbon black. Journal of Applied Physics. 1954;25(12):1503-9.

[39] Wu HZ, Roberts SG, Derby B. Residual stress distributions around indentations and scratches in polycrystalline $\mathrm{Al}_{2} \mathrm{O}_{3}$ and $\mathrm{Al}_{2} \mathrm{O}_{3} / \mathrm{SiC}$ nanocomposites measured using fluorescence probes. Acta Materialia. 2008;56(1):140-9.

[40] Cançado LG, Takai K, Enoki T, Endo M, Kim YA, Mizusaki H, Speziali NL, Jorio A, Primenta MA. Measuring the degree of stacking order in graphite by Raman spectroscopy. Carbon. 2008;46(2):272-5.

[41] Hinks JA, Haigh SJ, Greaves G, Sweeney F, Pan CT, Young RJ, Donnelly SE. Dynamic microstructural evolution of graphite under displacing irradiation. Carbon. 2014;68:273-84.

[42] Thrower PA. The burgers vector of dislocation loops in graphite. Philosophical Magazine. 1967;15(135):607-15.

[43] Frank O, Tsoukleri G, Riaz I, Papagelis K, Parthenios J, Ferrari AC, Geim AK, Novoselov KS, Galiotis C. Development of a universal stress sensor for graphene and carbon fibres. Nature Communications 2. 2011;255:1-7.

[44] Karthik C, Kane J, Butt DP, Windes WE, Ubic R. In situ transmission electron microscopy of electron-beam induced damage process in nuclear grade graphite. Journal of Nuclear Materials. 2011;412(3):321-6.

[45] Mironov BE, Freeman HM, Brown AP, Hage FS, Scott AJ, Westwood AVK, et al. Electron irradiation of nuclear graphite studied by transmission electron microscopy and electron energy loss spectroscopy. Carbon. 2015;83:106-17. 
[46] Heggie MI, Suarez-Martinez I, Davidson C, Haffenden G. Buckle, ruck and tuck: A proposed new model for the response of graphite to neutron irradiation. Journal of Nuclear Materials. 2011;413(3):150-5.

[47] McKenna AJ, Trevethan T, Latham CD, Young PJ, Heggie MI. Threshold displacement energy and damage function in graphite from molecular dynamics. Carbon. 2016;99:71-8. [48] Kelly BT, Martin WH, Price AM, Bland JT. The mechanism of dimensional changes in the crystals of graphites and carbons under fast neutron irradiation. Philosophical Magazine. 1966;14(128):343-56.

[49] Yi C, Chen X, Zhang L, Wang X, Ke C. Nanomechanical z-shape folding of graphene on flat substrate. Extreme Mechanics Letters. 2016;9(2):84-90.

[50] Chartier A, Van Brutzel L, Pannier B, Baranek P. Atomic scale mechanisms for the amorphisation of irradiated graphite. Carbon. 2015;91:395-407.

[51] Henson RW, Perks AJ, Simmons JHW. Lattice parameter and dimensional changes in graphite irradiated between 300 and $1350^{\circ} \mathrm{C}$. Carbon. 1968;6(6):798-804. 


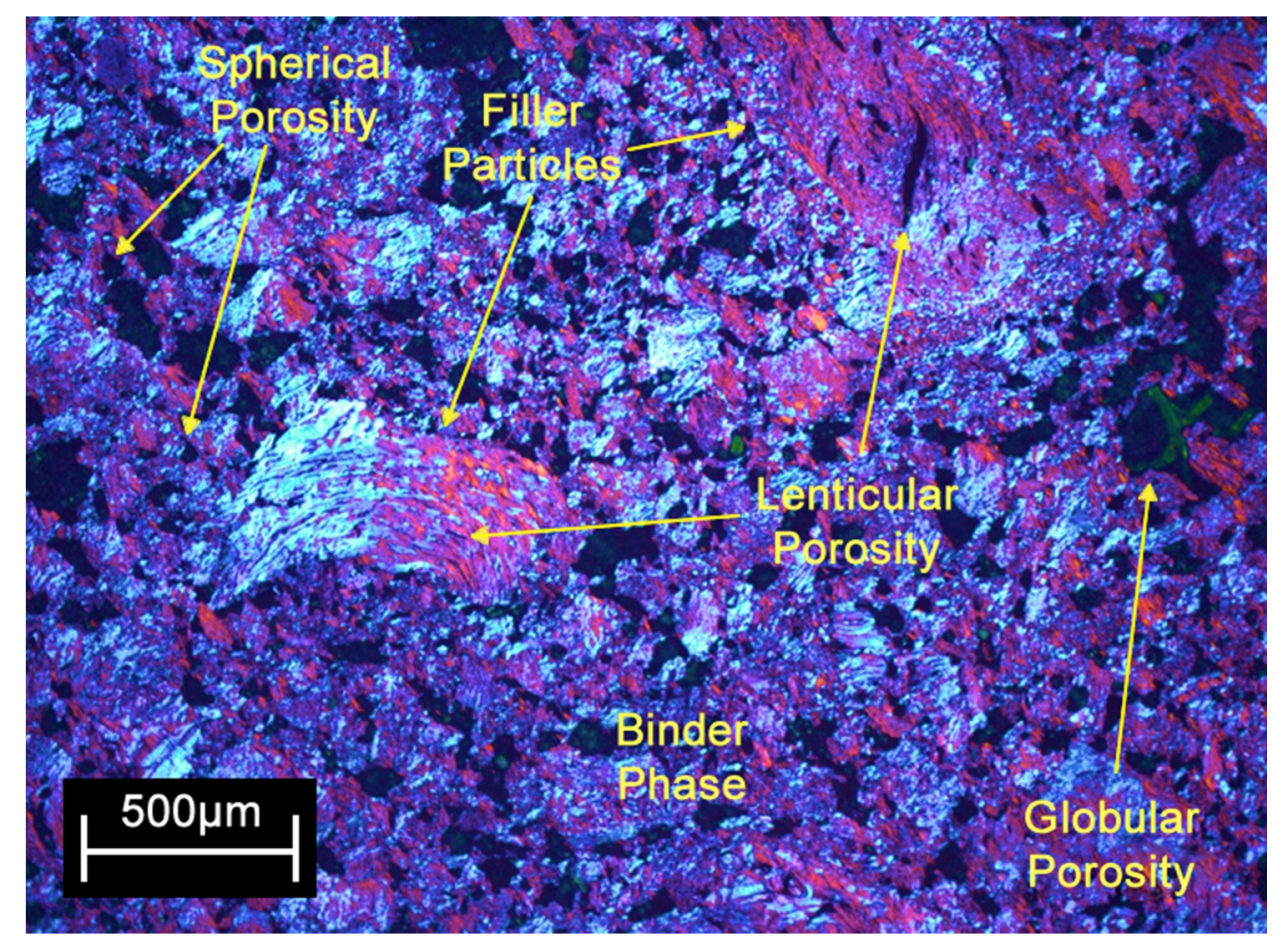

(a)

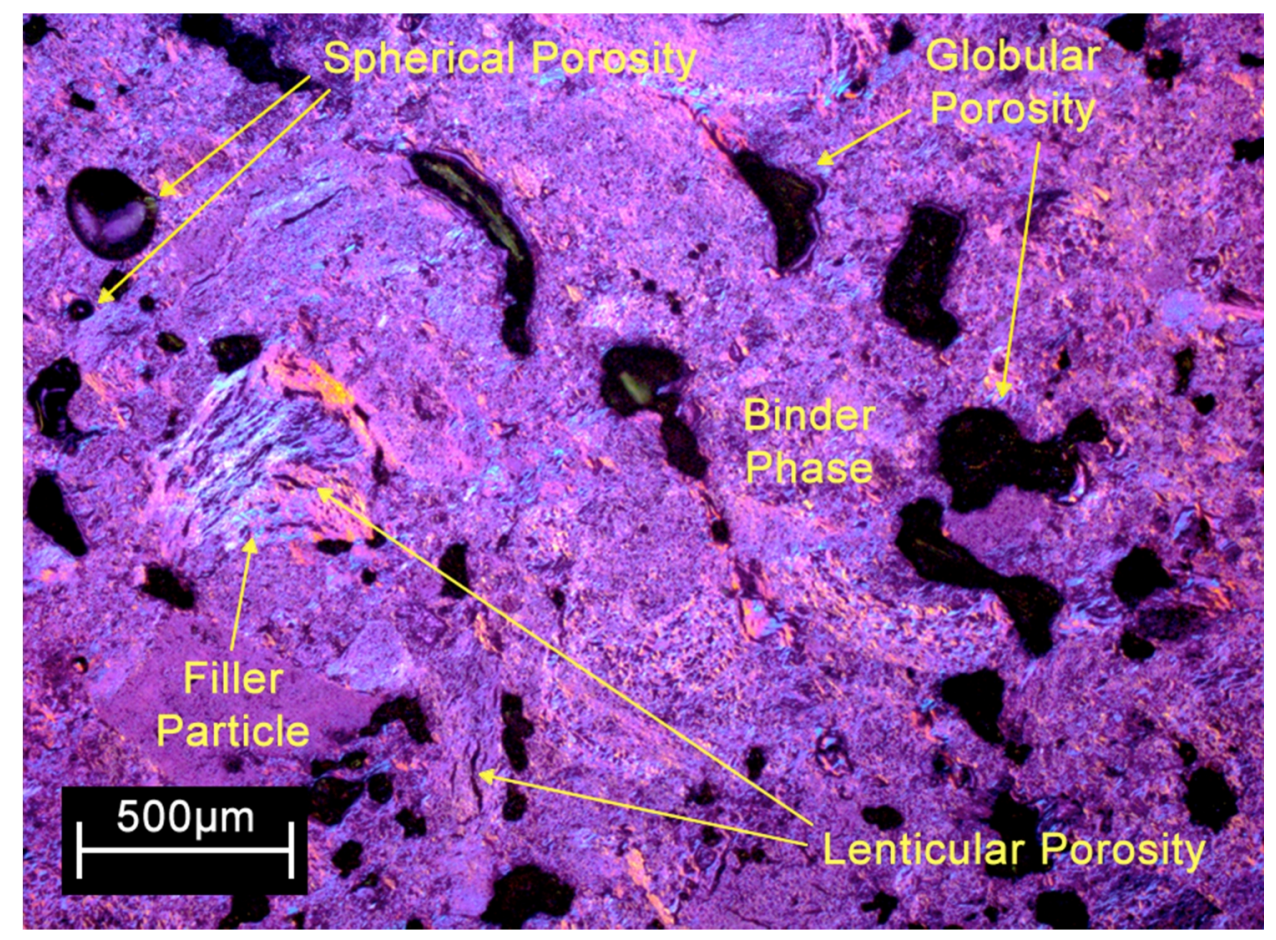

(b)

Fig. 1: Optical polarized light micrographs depicting: (a) BEPO and (b) PCEA graphite, both showing medium-grained filler particles and binder phase containing multidimensional pores. Filler grain size was approximately $650-950 \mu \mathrm{m}$ and pore area fractions were $13-22 \%$ in BEPO and PCEA grades. 


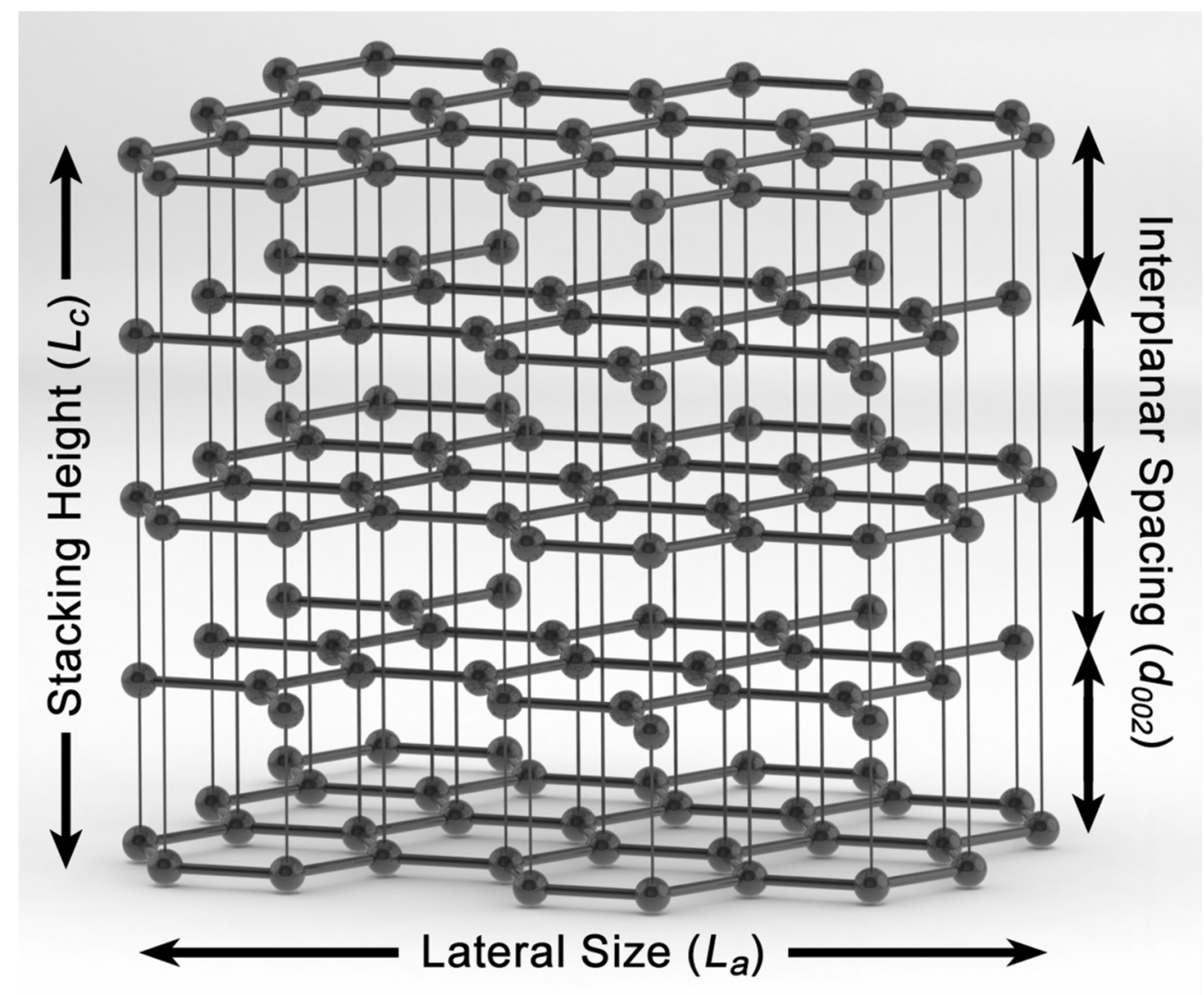

(a)
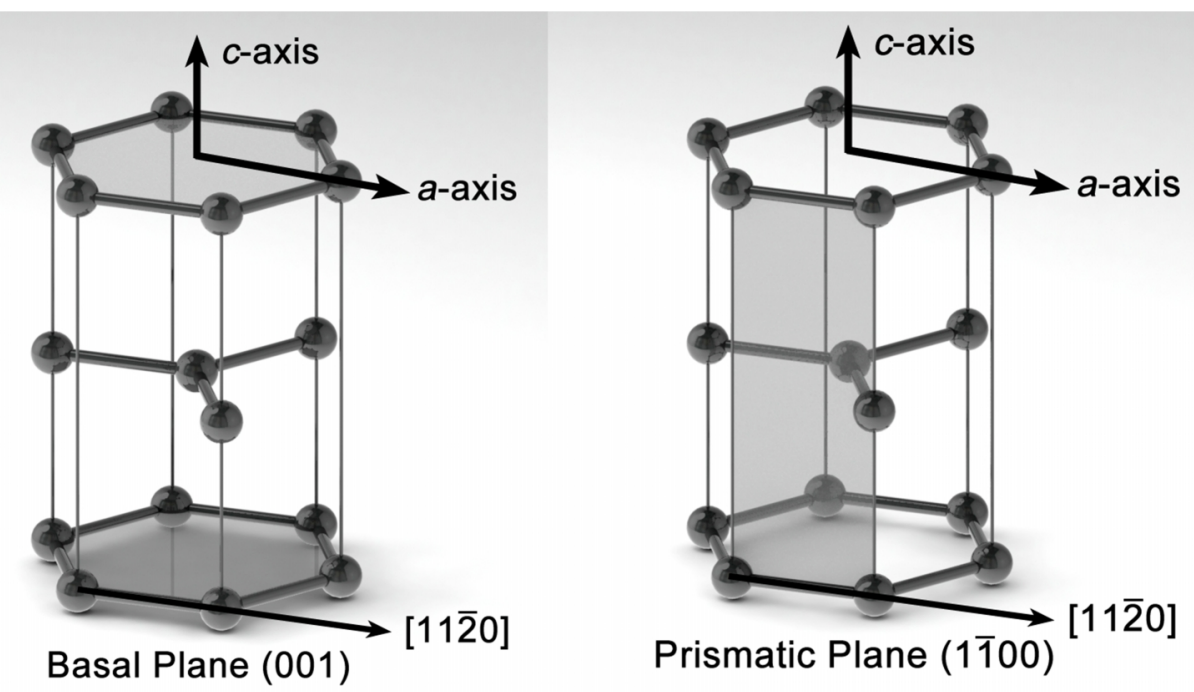

(b)

Fig. 2: Schematic diagrams showing: (a) the interplanar spacing, stacking height and lateral size of pristine graphite, and (b) the primary basal and prismatic planes and corresponding slip directions in graphite. 


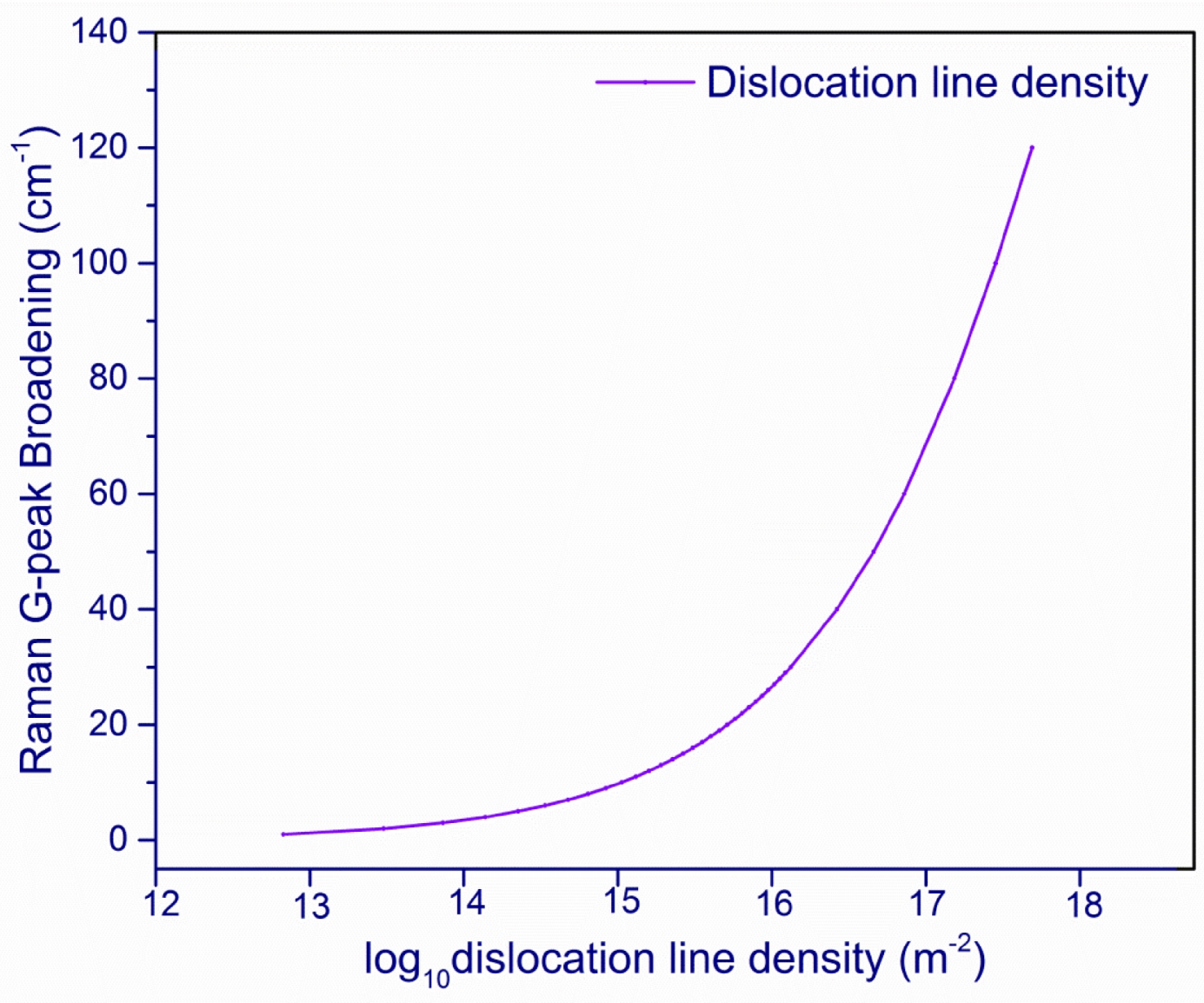

Fig. 3: Predicted broadening of the Raman G-peak resulting from an increase in dislocation density in graphite. A sharp incline in peak broadening can be seen at a critical dislocation density of $\sim 10^{15} \mathrm{~m}^{-2}$. 
(a)

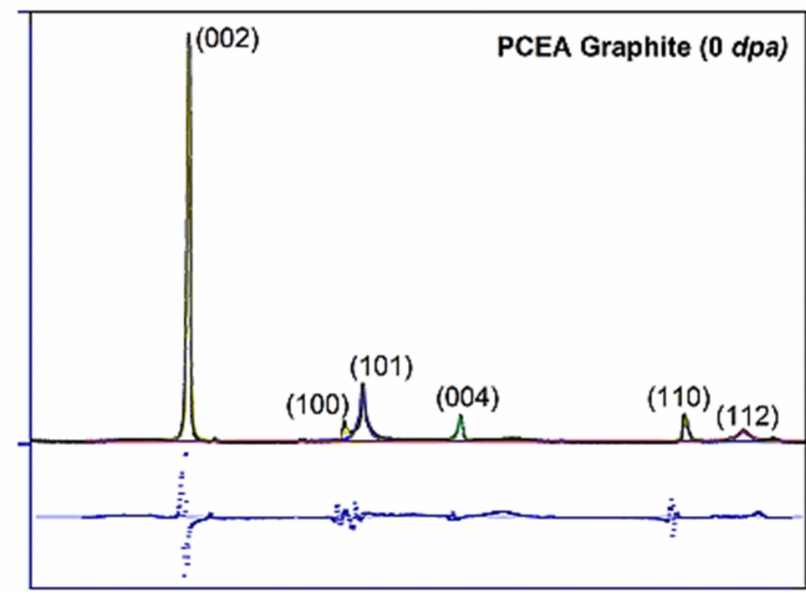

(b)

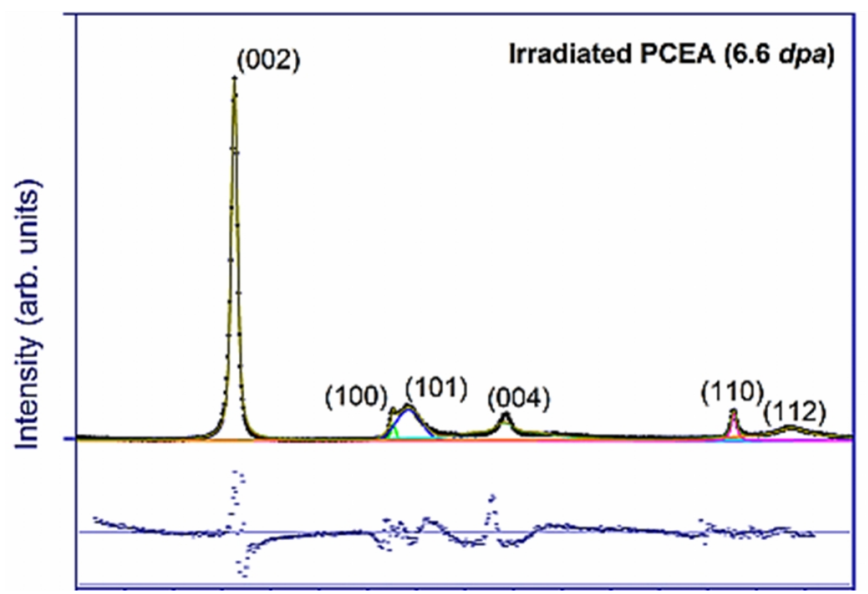

(c)

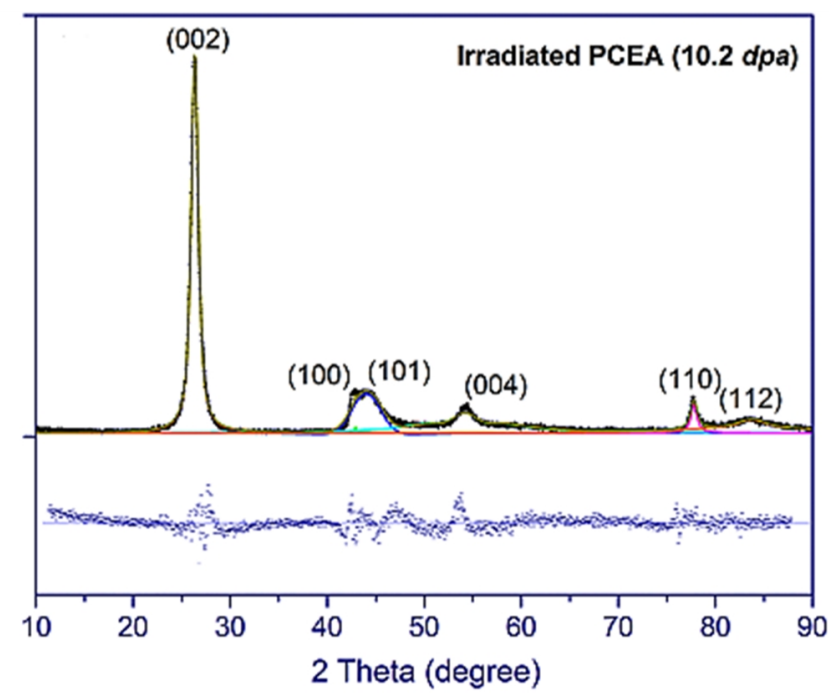

Fig. 4: XRD profiles of PCEA graphite: (a) virgin, (b) neutron irradiated at $900^{\circ} \mathrm{C}$ to a dose of $6.6 \mathrm{dpa}$, and (c) neutron irradiated at $900^{\circ} \mathrm{C}$ to a dose $10.2 \mathrm{dpa}$. The experimental diffraction patterns have been deconvoluted to produce individual Bragg peaks each fitting a $p V$ function. The degree of fit is given in the residual plots provided underneath each XRD pattern. 


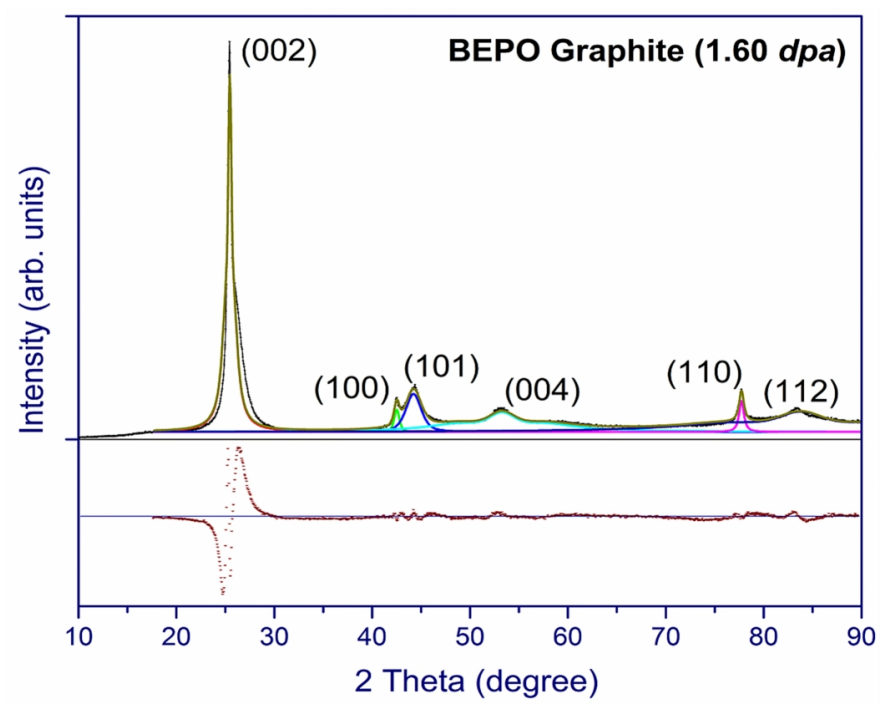

Fig. 5: XRD profile of BEPO graphite. The experimental pattern has been deconvoluted to produce individual Bragg peaks each fitting a $p V$ function. The degree of fit is given in the residual plot underneath the XRD pattern. 


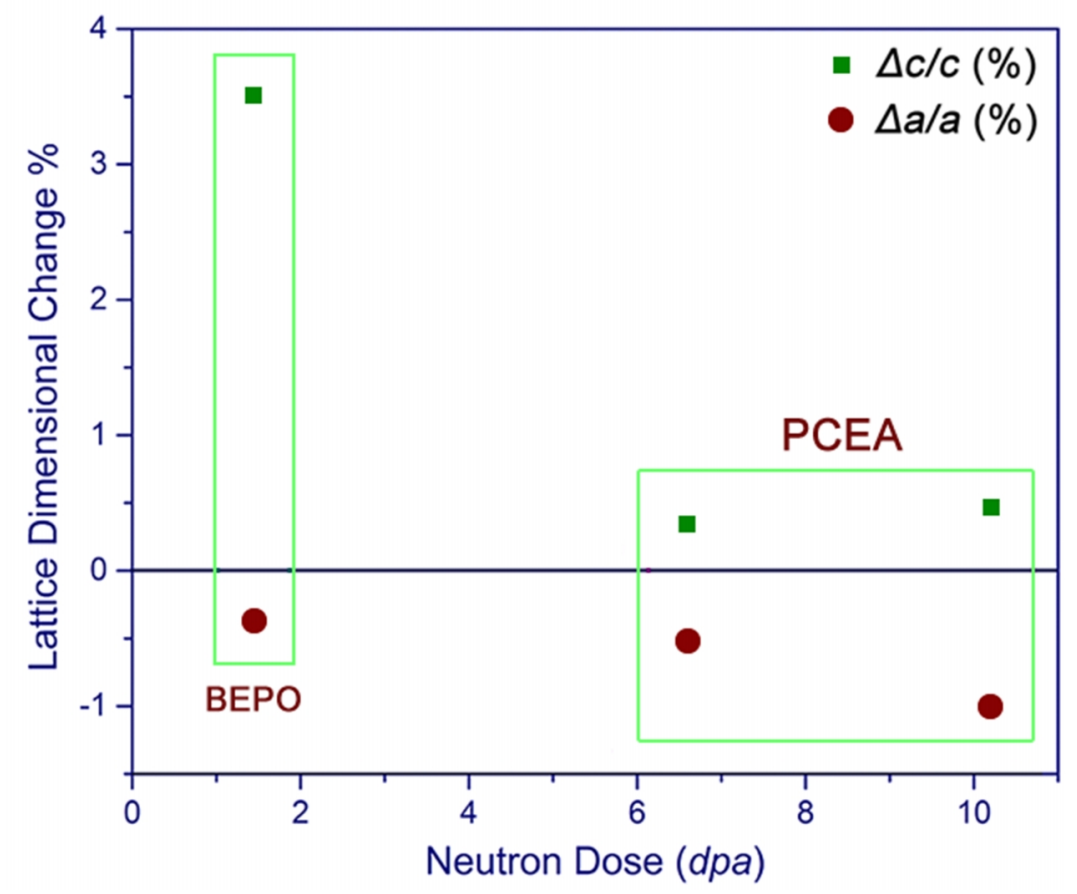

(a)

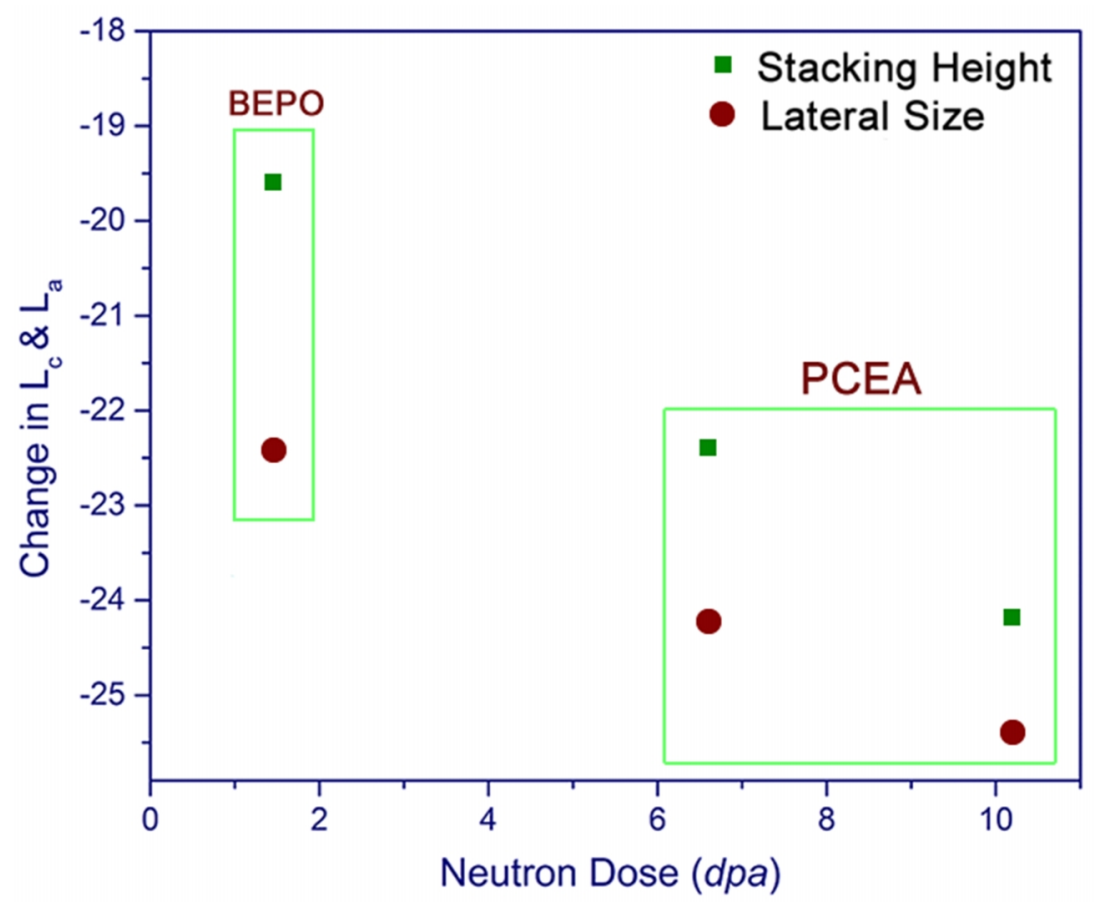

(b)

Fig. 6: The change in lattice properties of iradiated BEPO and PCEA graphite: (a) dimensional change, and (b) stacking height and lateral size. 


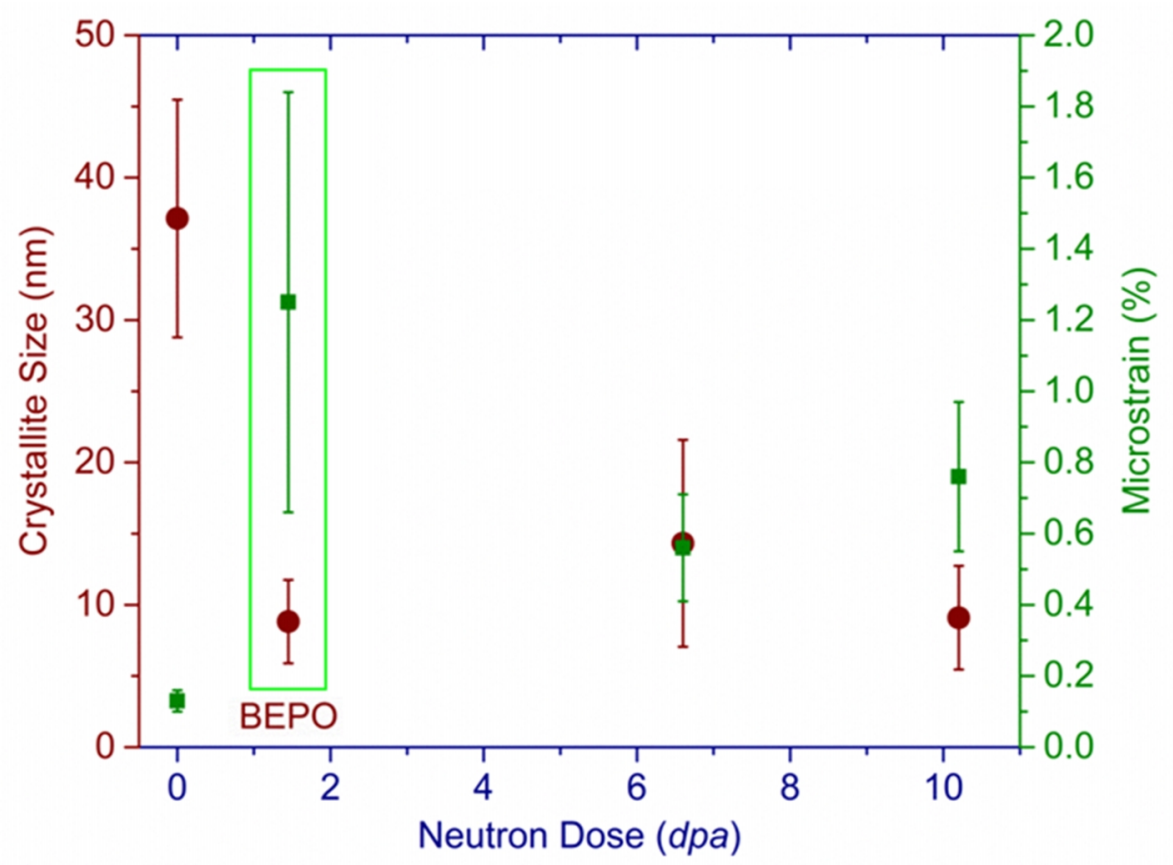

(a)

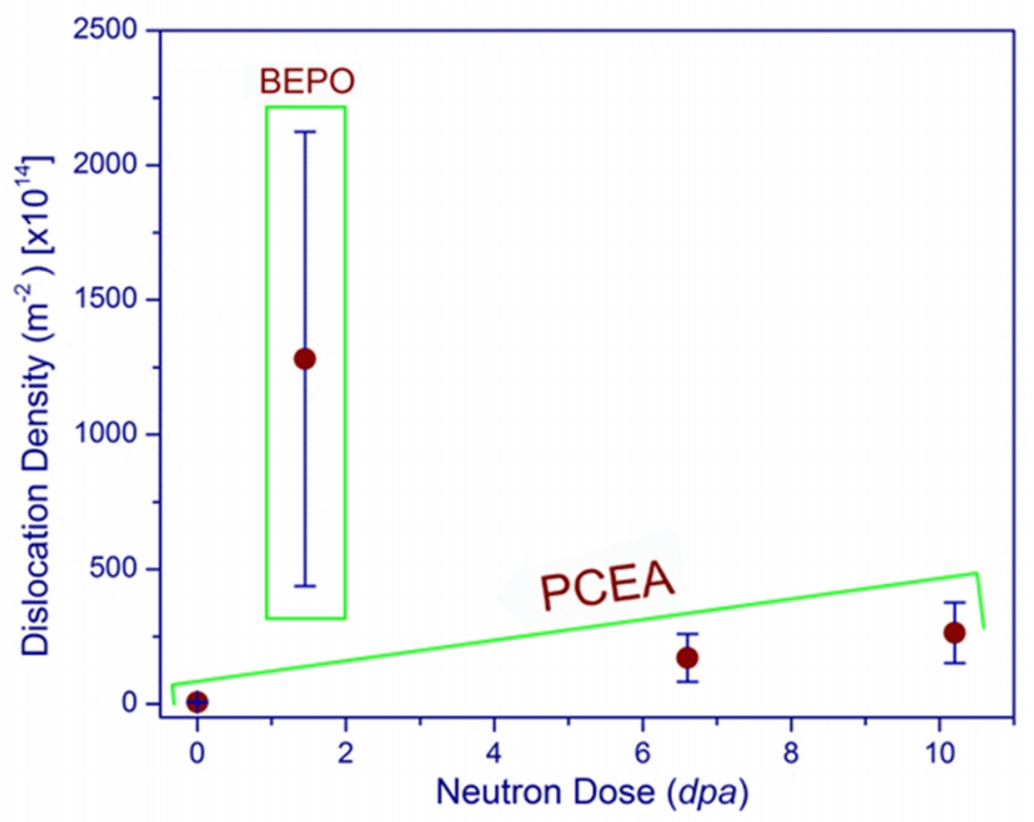

(b)

Figure 7: The variation of: (a) average crystallite size and lattice micro-strain, and (b) average density of dislocations in BEPO and PCEA graphite as a function of neutron dose. 
(a)

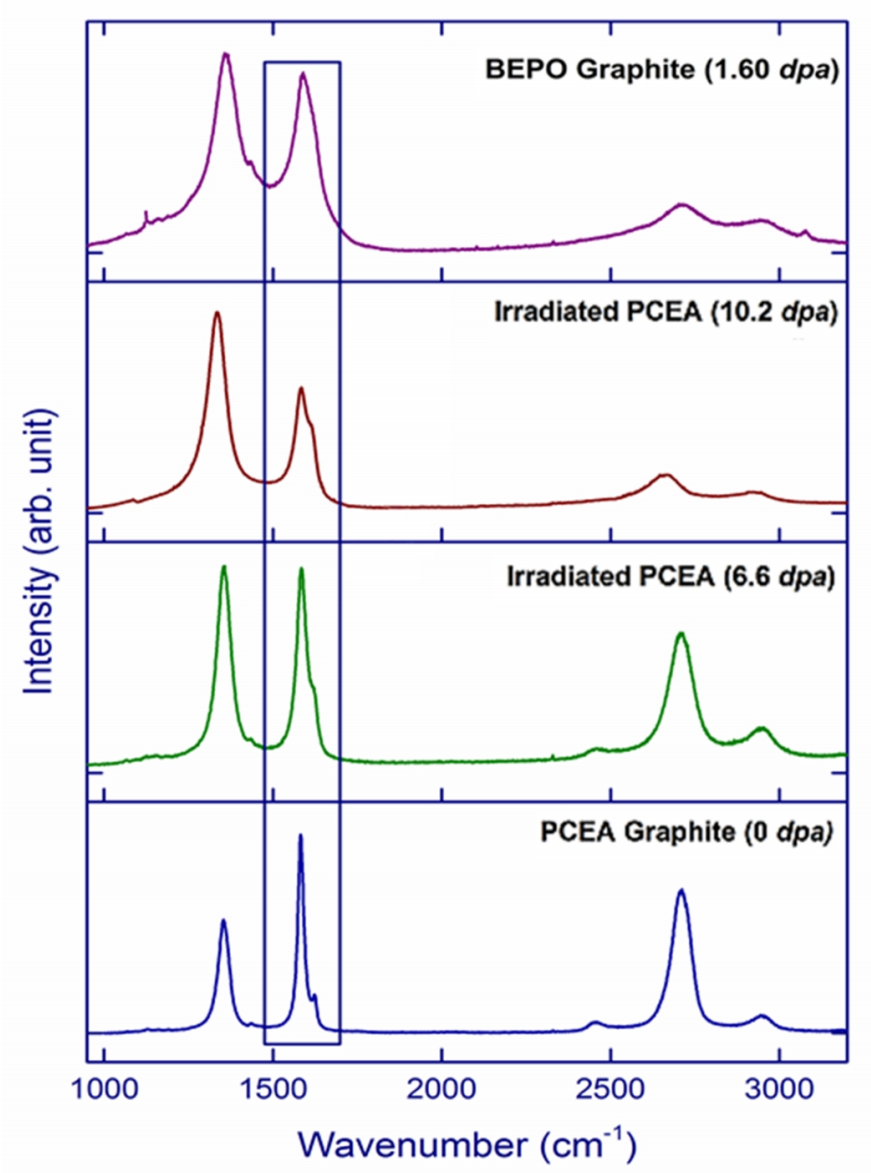

(b)

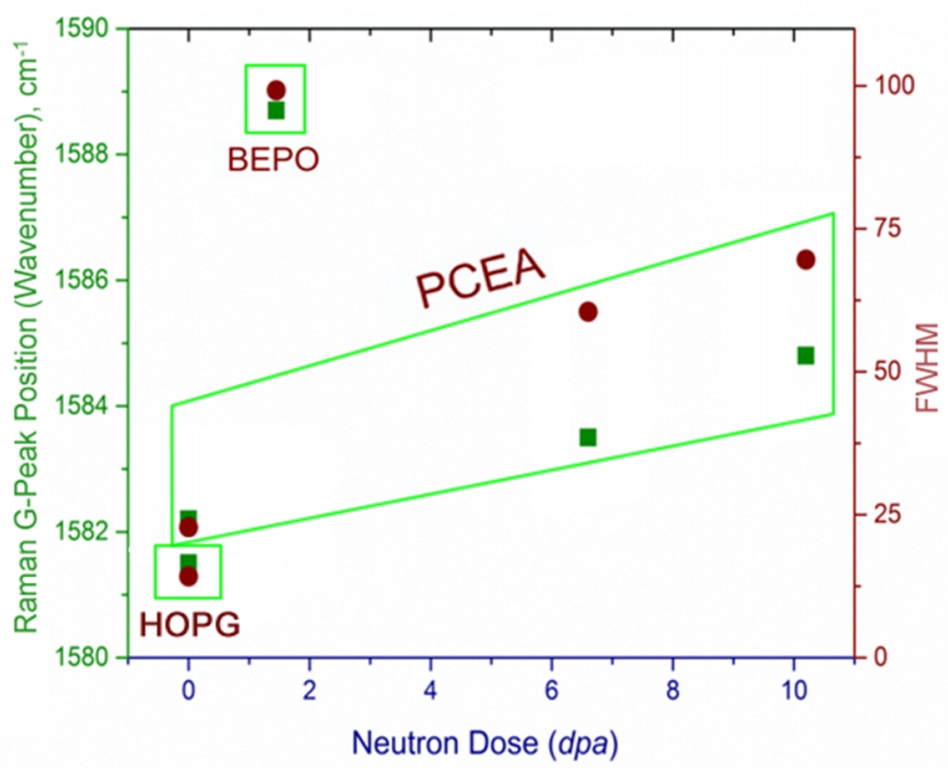

Fig. 8: (a) The Raman spectra showing Raman $D, G$ (inside box), $D$ and $2 D$ peaks, and (b) Raman G-peak positions and FWHMs $\left(\mathrm{cm}^{-1}\right)$ of the Raman sprectra for PCEA (virgin and irradiated), BEPO, and the HOPG reference graphite. 
(a)

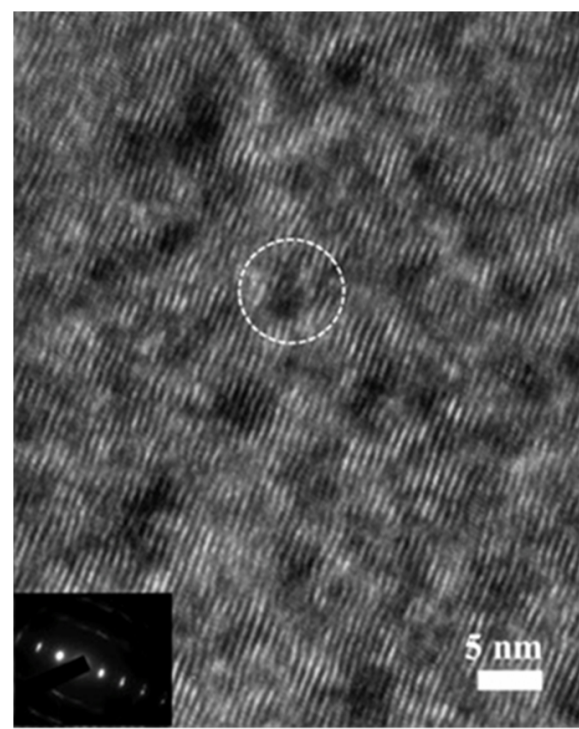

(b)

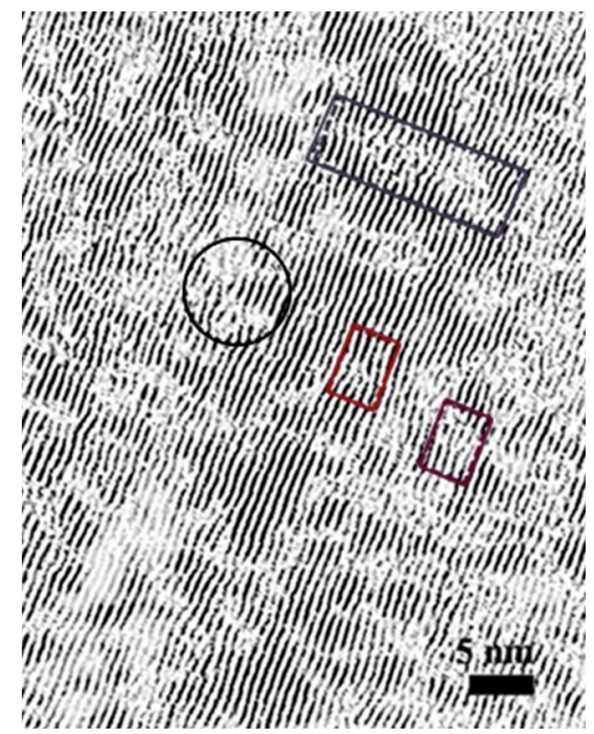

Fig. 9: HRTEM images of: (a) virgin PCEA graphite, and (b) noise filtered lattice image of (a). Lattice defects such as prismatic edge dislocations have been highlighted by the rectangular boxes. 


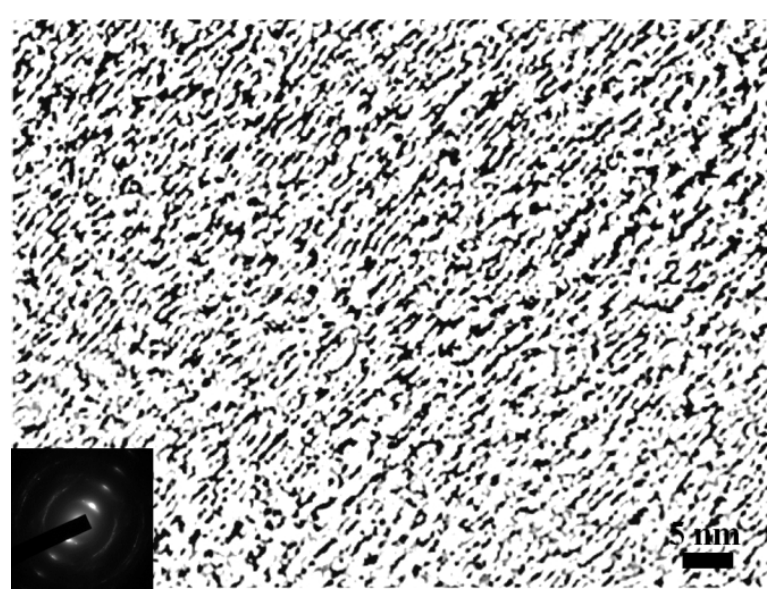

(a)

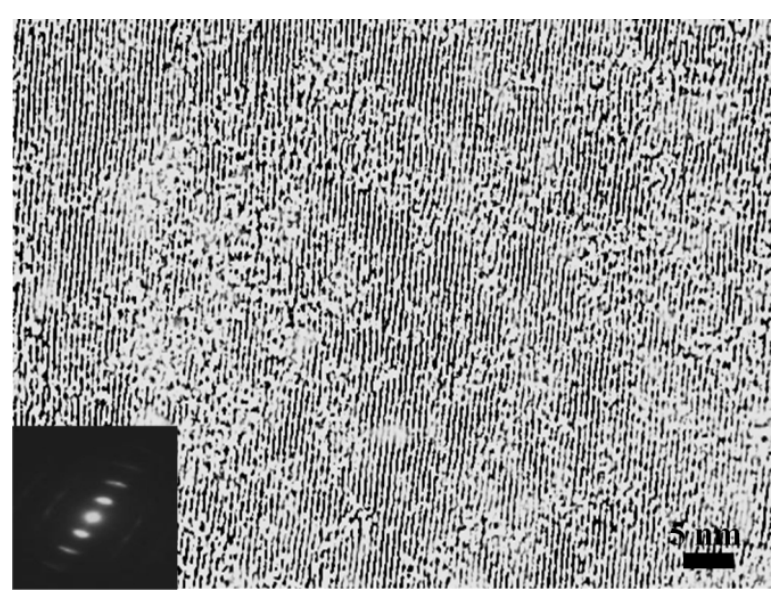

(b)

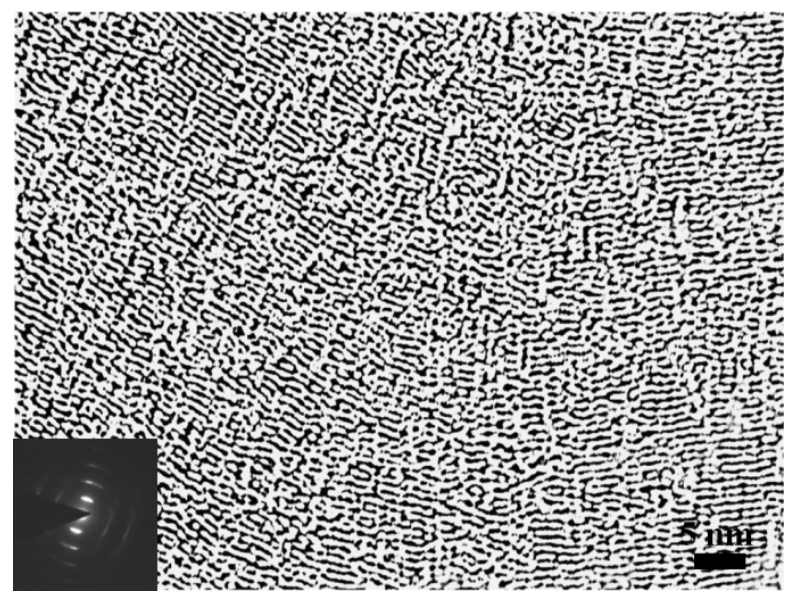

(c)

Fig. 10: Filtered HRTEM images of basal layers in: (a) irradiated BEPO (1.60 dpa), (b) irradiated PCEA (6.6 dpa), and (c) irradiated PCEA (10.2 dpa). The black colour represents the basal layer planes of the graphite and the white colour represents the space between those layer planes and discontinuities in the layer planes i.e. lattice defects. 


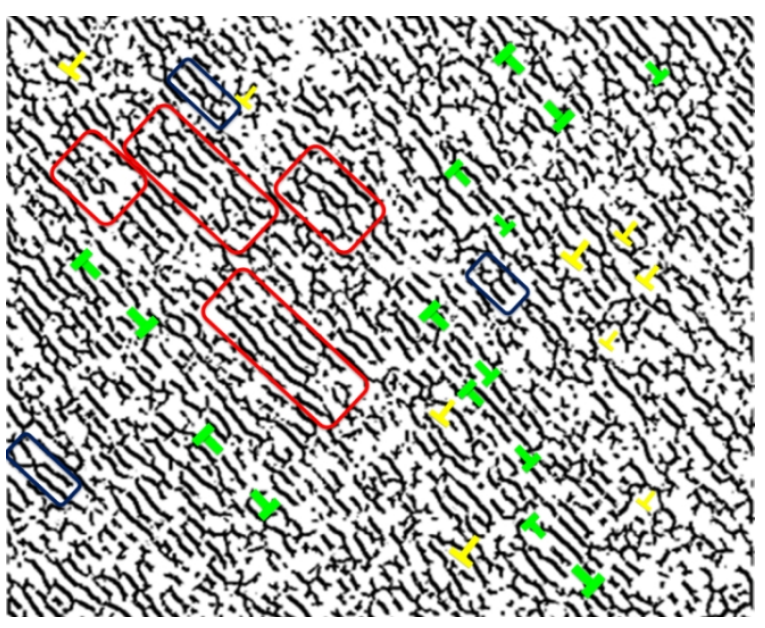

(a)

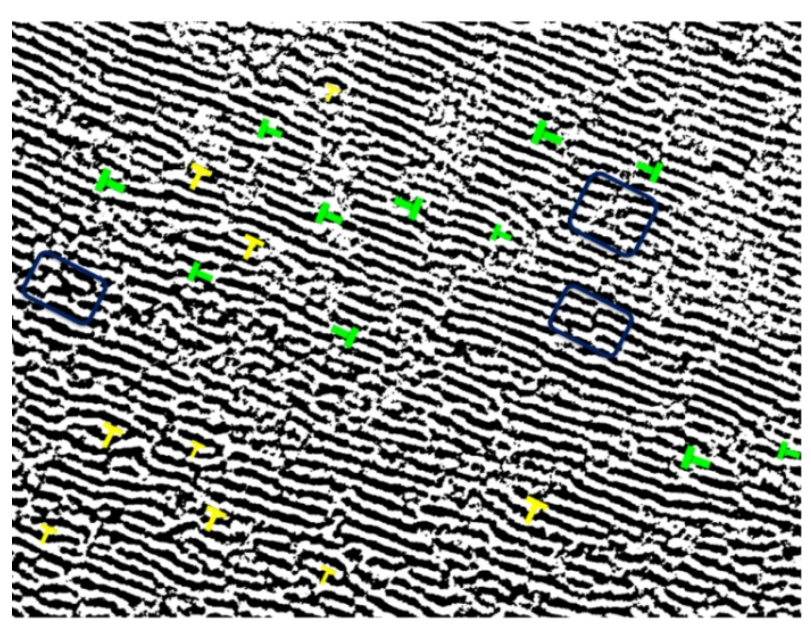

(b)

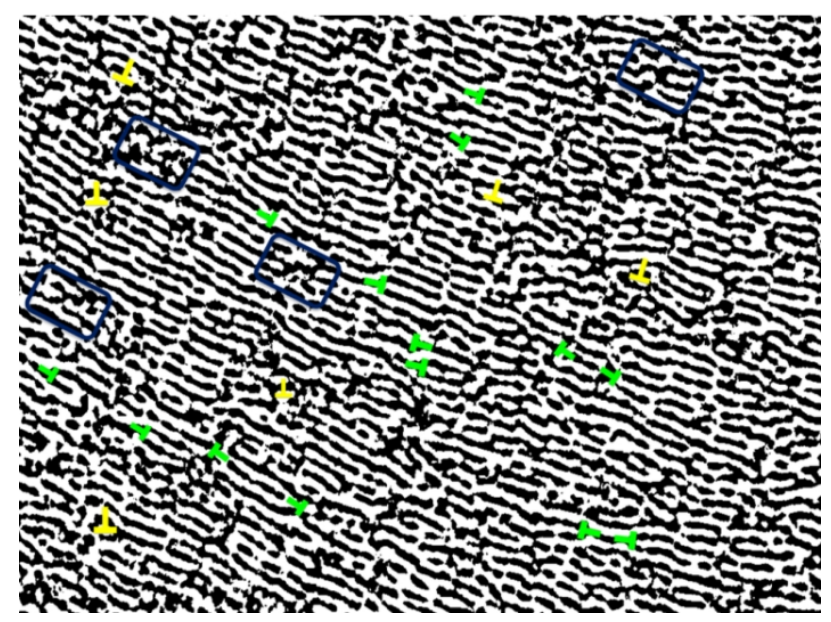

(c)

Fig. 11: The different types of dislocations observed in: (a) irradiated BEPO (1.60 dpa), (b) irradiated PCEA (6.6 dpa), and (c) irradiated PCEA (10.2 dpa). Basal dislocations are shown in yellow. Prismatic edge dislocations are in green. Red rectangular boxes show evidence of layer planes folding to form torturous graphitic sheets. 


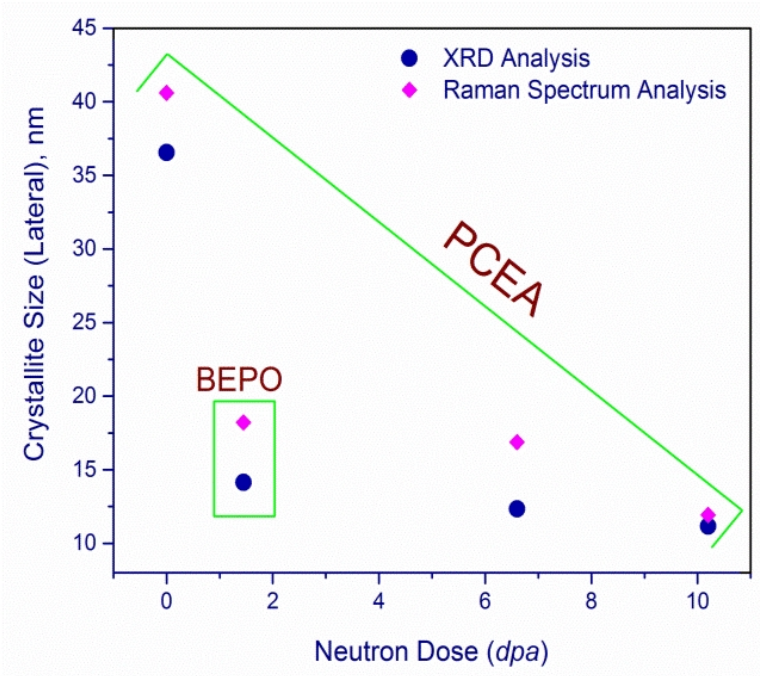

(a)

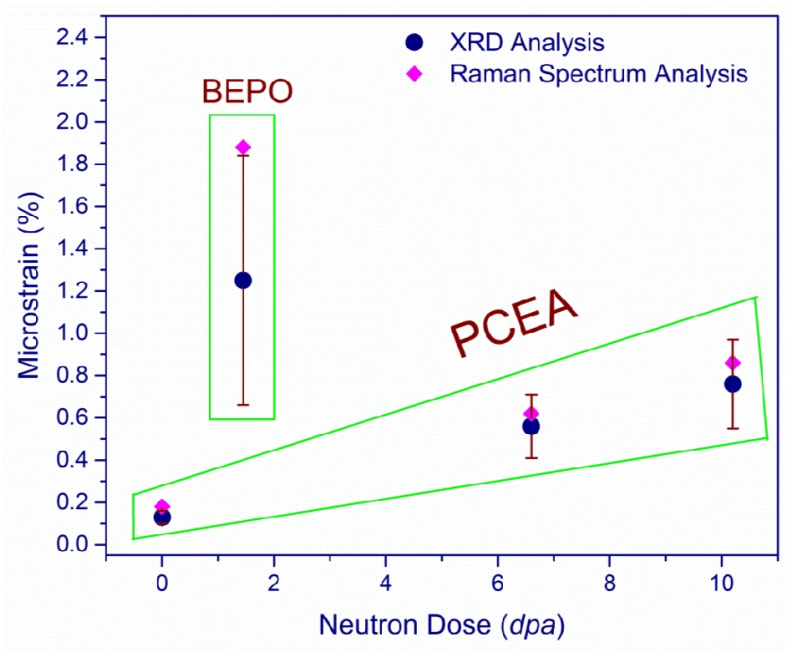

(b)

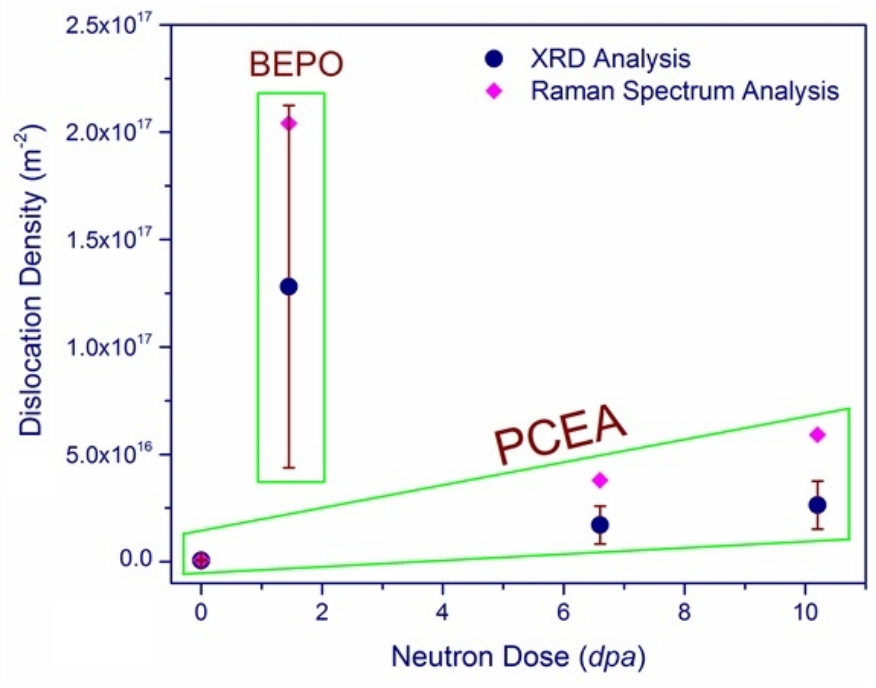

(c)

Fig. 12: The results from $X R D$ and Raman spectroscopy show coefficients of variation for: (a) crystallite lateral size, (b) micro-strain, and (c) dislocation density. 
Table 1: Basal, prismatic and pyramidal slip systems in hexagonal close packed structures.

\begin{tabular}{|c|c|c|c|}
\hline Dislocation Type & Plane & Direction & Burgers Vector \\
\hline Basal, $<\mathrm{c}>$ & $(0002)$ & $<11 \overline{2} 0>$ & $\begin{array}{c}\bar{b}=\frac{a}{3}<11 \overline{2} 0>, \\
(\bar{b} \| a-\text { axis })\end{array}$ \\
\hline Prismatic, $<$ a $>$ & $(1 \overline{1} 00)$ & $<11 \overline{2} 0>$ & $\begin{array}{c}\bar{b}=\frac{a}{3}<11 \overline{2} 0> \\
(\bar{b} \| c-\text { axis })\end{array}$ \\
\hline $\begin{array}{c}\text { Pyramidal, }<\mathrm{a}> \\
<\mathrm{c}+\mathrm{a}>\end{array}$ & $\begin{array}{l}(10 \overline{1} 1) \\
(11 \overline{2} 2)\end{array}$ & $\begin{array}{l}<11 \overline{2} 0> \\
<11 \overline{2} 3>\end{array}$ & $\begin{array}{l}\bar{b}=\frac{a}{3}<11 \overline{2} 0> \\
\bar{b}=\frac{a}{3}<11 \overline{2} 3>\end{array}$ \\
\hline
\end{tabular}


Table 2: A summary of the measured microstructural characteristics of virgin and irradiated PCEA and irradiated BEPO graphite determined using XRD spectral analysis.

\begin{tabular}{|c|c|c|c|c|c|c|c|c|c|c|}
\hline \multirow{2}{*}{$\begin{array}{c}\text { Graphite } \\
\text { Grade }\end{array}$} & \multirow{2}{*}{$\begin{array}{c}\text { Neutron } \\
\text { Dose } \\
\text { (dpa) }\end{array}$} & \multirow{2}{*}{$\begin{array}{c}\text { Temperature, } \\
T(\mathbf{K})\end{array}$} & \multirow{2}{*}{$\begin{array}{c}\text { Interplanar } \\
\text { Spacing, } \\
d_{002} \\
(\mathrm{~nm})\end{array}$} & \multicolumn{2}{|c|}{$\begin{array}{c}\text { Lattice } \\
\text { Parameters (nm) }\end{array}$} & \multirow[b]{2}{*}{$c / a$} & \multicolumn{2}{|c|}{$\begin{array}{c}\text { Crystallite } \\
\text { Dimensions (nm) }\end{array}$} & \multirow{2}{*}{$\begin{array}{c}\text { Degree of } \\
\text { Graphitisation, } \\
\bar{g} \\
(\%)\end{array}$} & \multirow{2}{*}{$\begin{array}{c}\mathrm{V}\left(\AA^{3}\right) \\
=a^{2} \times c \times \sin \left(60^{\circ}\right)\end{array}$} \\
\hline & & & & $c$ & $a$ & & $\begin{array}{c}\text { Stacking } \\
\text { Height } \\
\left(L_{c}\right)\end{array}$ & $\begin{array}{c}\text { Lateral } \\
\text { Size } \\
\left(L_{a}\right)\end{array}$ & & \\
\hline \multirow{2}{*}{ PCEA } & 0 & 298 & 0.33798 & 0.67596 & 0.24624 & 2.745 & 33.34 & 36.56 & 87.47 & 35.496 \\
\hline & 10.2 & 1173 & 0.33956 & 0.67912 & 0.24378 & 2.786 & 9.17 & 11.17 & 79.81 & 34.822 \\
\hline BEPO & 1.60 & $373-393$ & 0.34984 & 0.69967 & 0.24532 & 2.852 & 13.75 & 14.14 & 29.9 & 36.465 \\
\hline
\end{tabular}


Table 3: A summary of the measured crystallite size and dislocation density measurements of PCEA and BEPO graphite determined using XRD line profile analysis.

\begin{tabular}{|c|c|c|c|c|c|}
\hline $\begin{array}{c}\text { Graphite } \\
\text { Grade }\end{array}$ & $\begin{array}{c}\text { Neutron } \\
\text { Dose (dpa) }\end{array}$ & $\begin{array}{c}\text { Defect Density due to } \\
\text { Crystallite Size } \\
\left.\left[\times \mathbf{1 0}^{\mathbf{1 4}}\right] \mathbf{( m}^{-\mathbf{2}}\right)\end{array}$ & $\begin{array}{c}\text { Defect Density due to } \\
\text { Micro-Strain } \\
\left.\left[\times \mathbf{1 0}^{\mathbf{1 4}}\right] \mathbf{( m}^{-\mathbf{2}}\right)\end{array}$ & $\begin{array}{c}\text { Average Total Defect } \\
\text { Density } \\
\left.\left[\times \mathbf{1 0}^{\mathbf{1 4}}\right] \mathbf{( m}^{-\mathbf{2}}\right)\end{array}$ & $\begin{array}{c}\text { Average Micro- } \\
\text { Strain } \\
(\mathbf{\%})\end{array}$ \\
\hline \multirow{2}{*}{ PCEA } & 0 & $58.30 \pm 36.78$ & $0.75 \pm 0.15$ & $6.59 \pm 2.40$ & $0.13 \pm 0.03$ \\
\cline { 2 - 6 } & 6.6 & $1109.31 \pm 520.53$ & $27.50 \pm 15.0$ & $264.05 \pm 112.31$ & $0.56 \pm 0.15$ \\
\hline BEPO & 10.2 & $1984.34 \pm 798.63$ & $39.20 \pm 18.98$ & $1281.04 \pm 843.80$ & $1.25 \pm 0.59$ \\
\hline
\end{tabular}


Table 4: Structural characteristics of virgin and irradiated PCEA and BEPO graphite determined using Raman spectral analyses.

\begin{tabular}{|c|c|c|c|c|c|c|}
\hline \multirow{2}{*}{$\begin{array}{c}\text { Graphite } \\
\text { Grade }\end{array}$} & \multirow{2}{*}{$\begin{array}{c}\text { Neutron } \\
\text { Dose } \\
\text { (dpa) }\end{array}$} & \multirow{2}{*}{$\begin{array}{c}\text { Crystallite } \\
\text { Lateral Size, } \mathrm{L}_{\mathbf{a}} \\
(\mathbf{n m})\end{array}$} & \multicolumn{2}{|c|}{$\begin{array}{c}\text { Biaxial Micro-Strain } \\
\text { (axes } x \text { - and } y \text {-define a reference plane) }\end{array}$} & \multirow{2}{*}{$\begin{array}{c}\text { Average Micro- } \\
\text { Strain } \\
(\%)\end{array}$} & \multirow{2}{*}{$\begin{array}{c}\text { Dislocation density } \\
\left.\qquad \times 10^{14}\right] \\
\left(\mathrm{m}^{-2}\right)\end{array}$} \\
\hline & & & $\begin{array}{c}\text { Micro-Strain } \\
\text { (x-Direction) } \\
(\%)\end{array}$ & $\begin{array}{c}\text { Micro-Strain } \\
\text { (y-direction) } \\
(\%)\end{array}$ & & \\
\hline \multirow{3}{*}{ PCEA } & 0 & 40.61 & 0.21 & 0.08 & 0.18 & 7.59 \\
\hline & 6.6 & 16.88 & 0.70 & 0.26 & 0.62 & 379.94 \\
\hline & 10.2 & 11.94 & 0.99 & 0.37 & 0.86 & 591.31 \\
\hline BEPO & 1.60 & 18.21 & 2.15 & 0.80 & 1.88 & 2041.17 \\
\hline
\end{tabular}

